Wind Energ. Sci. Discuss., https://doi.org/10.5194/wes-2018-53

Manuscript under review for journal Wind Energ. Sci.

Discussion started: 6 August 2018

(c) Author(s) 2018. CC BY 4.0 License.

\title{
1 Towards the North Sea wind power revolution
}

2 Jens N. Sørensen ${ }^{1}$, Gunner C. Larsen ${ }^{2}$

$3 \quad{ }^{1}$ DTU Wind Energy, Fluid Mechanics, 2800 Lyngby, Denmark

$4 \quad{ }^{2}$ DTU Wind Energy, Wind Turbine Loads and Control, 4000 Roskilde, Denmark

5

6 Correspondence to: Jens N. Sørensen (jnso@dtu.dk)

7 Abstract. The present work assesses the potential of a massive exploitation of offshore wind power in the North Sea by 8 combining a meteorological model with a cost model that includes a bathymetric analysis of the water depth of the North

9 Sea. The overall objective is to assess if the wind power in the North Sea can deliver the total consumption of electricity

10 in Europe and to what prize as compared to conventional onshore wind energy. The meteorological model is based on the assumption that the exploited area is so large, that the wind field between the turbines is in equilibrium with the atmospheric boundary layer. This makes it possible to use momentum analysis to determine the mutual influence between the atmospheric boundary layer and the wind farm, with the wind farm represented by an average horizontal force component corresponding to the thrust. The cost model includes expressions for the most essential wind farm cost elements, such as costs of wind turbines, support structures, cables and electrical substations, as well as operation and maintenance as function of rotor size, interspatial distance between the turbines, and water depth. The numbers used in the cost model are based on previous experience from offshore wind farms, and is therefore somewhat conservative. The analysis shows that the lowest energy cost is obtained for a configuration of large wind turbines erected with an interspatial distance of about eight rotor diameters. A part of the analysis is devoted to assessing the relative costs of the various elements of the cost model in order to determine the components with the largest potential for reducing the cost price. As an overall finding, it is shown that the power demand of Europe, which is $0.4 \mathrm{TW}$ or about $3500 \mathrm{TWh} /$ year, can be fulfilled by exploiting an area of $190.000 \mathrm{~km}^{2}$, corresponding to about $1 / 3$ of the North Sea, with 100.000 wind turbines of generator size $13 \mathrm{MW}$ on water depths up to $45 \mathrm{~m}$ at a cost price of about $7.5 €$ cents $/ \mathrm{kWh}$.

24

25

26

27

28

29

30

31

32

33

\section{Introduction}

Although offshore wind energy has grown significantly over the past years, it only contributes with about $3 \%$ of the total deployed wind energy. Measured by the investments and effort by the European wind energy industry to reduce the cost of offshore wind power, it also is clear that offshore wind power will become a very important part of the future European power production. As an illustration of this (see Fig. 1), 15 new offshore wind farms are at the moment under development in Europe, contributing with an installed capacity of more than $4.000 \mathrm{MW}$, and in addition many offshore wind farms are planned in the European seas (The European offshore wind industry, 2016). An important question is to what extent the North Sea can be exploited with respect to a massive penetration of wind turbines, and what are the economic aspects of doing this. As an overall objective, we here address the question if the North Sea can deliver the total consumption of electricity in Europe and to what prize. To answer these questions it is required to determine the available wind resources as well as the associated costs of erecting and operating wind turbines in the ocean. The first question regarding the available wind resources is not trivial, as the presence of the turbines due to mutual wake effects alters the local wind conditions. Hence, erecting wind turbines close to each other will reduce the wind speed and by this the efficiency of the total power production. On the other hand, if the turbines are too far from each other, the full potential of the wind resources in the North Sea will not be achieved. The most important parameter in this context is the mutual distance 
Wind Energ. Sci. Discuss., https://doi.org/10.5194/wes-2018-53

Manuscript under review for journal Wind Energ. Sci.

Discussion started: 6 August 2018

(c) Author(s) 2018. CC BY 4.0 License.

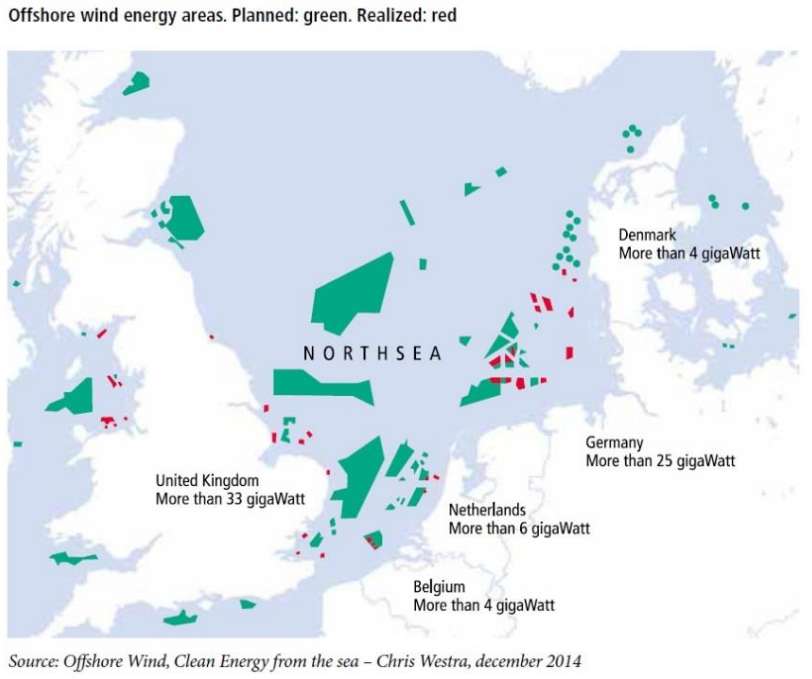

Figure 1: Planned and realized wind farms in the North Sea (Source: Offshore Wind, Clean Energy from the sea - Chris Westra, December 2014).

between the turbines, measured in rotor diameters, which is a reference length for wind farms. Today, in a typical wind farm, such as Rødsand or Horns Rev, the turbines are located 6-7 diameters from each other in order to diminish the wake effects. However, in a very large wind farm covering a main part of the North Sea this number may be different. Another important parameter is the size of the turbines, measured in installed generator power, or, alternatively, in rotor diameter. While the size of wind turbines erected onshore, due to visual impact, noise and other issues related to the lack of public acceptance, has stabilized on a maximum of about 3.5 MW, the size of wind turbines erected offshore is still increasing because of the influence of size on the reduction of cost of energy, which is much more pronounced offshore than onshore. Today, the biggest offshore wind turbines have a diameter of more than $160 \mathrm{~m}$ and an installed generator capacity of 8 MW. An important parameter in a cost analysis of offshore wind turbines is water depth, as the price of foundations and substructures heavily depends on water depth. Therefore, an economic analysis requires to be complemented with a bathymetric analysis. Other important economic parameters are costs of installation as well as operation and maintenance, both of which are substantially increased because of the harsh weather conditions appearing in the North Sea.

In the following, we address the various issues related to a massive penetration of wind power in the North Sea, including an assessment of the available wind power, the bathymetry of the North Sea, and an economic analysis. As wind farm design parameters we employ the interspatial distance between the turbines, measured in rotor diameters, and the turbine size, which here is varied in the range from about $3 \mathrm{MW}$ to $20 \mathrm{MW}$. Furthermore, to simplify the analysis, issues and constraints, like fishery, sailing routes, political aspects, etc., are not taking into consideration. These aspects are certainly of importance, but outside the scope of the present analysis.

The paper is organized as follows. In chapter 2 we introduce the theory for the employed models, which is divided into a model for the power production and a model for the economic assessment of the installation. In section 3 results are shown and discussed, and in section 4 we conclude and outline the main findings.

\section{Theory}

The aim of this study is twofold - 1) to assess the wind power area density dependency on wind turbine size and spacing; 
Wind Energ. Sci. Discuss., https://doi.org/10.5194/wes-2018-53

Manuscript under review for journal Wind Energ. Sci.

Discussion started: 6 August 2018

(c) Author(s) 2018. CC BY 4.0 License.

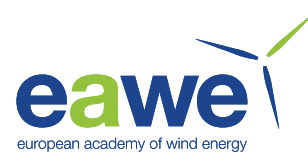

and 2) to determine the optimal wind turbine size and interspacing (i.e. wind farm topology) from an economic perspective. The economic analysis is based on relatively simple models of foundation costs, cost of wind turbines, cost of internal wind farm electrical infrastructure, and costs of operation and maintenance (O\&M). Costs of lifetime fatigue degradation of turbine components has, however, been neglected, but could, in a first order approximation, be considered proportional to O\&M costs. A more detailed approach is described by Rethoré et al. (2016), where cost of component fatigue degradation is estimated using aeroelastic simulations of individual wind farm turbines exposed to unsteady wake affected inflow conditions modeled using the Dynamic Make Meandering model (Larsen et al., 2008). In the following subsections we describe and discuss the models used for wind resource estimation, for wind farm layout and for the cost estimates on which the economic optimization will be based.

\subsection{Ressource estimation}

The model we employ to assess the wind power resource was originally developed by Templin (1974) and later developed further by Frandsen and Madsen (2003) (see also Frandsen, 2005). The model is based on the assumption that the wind farm is so large, that the wind field inside the wind farm is in equilibrium with the atmospheric boundary layer (ABL). This makes it possible to use momentum analysis to determine the mutual influence between the atmospheric boundary layer and the wind farm, with the wind farm represented by an average horizontal force component, corresponding to the thrust, and the relative distance between the turbines as the main parameters. In the model it is assumed that the influence of the wind turbines create two logarithmic boundary layers, which are connected at hub height by the shear forces exerted by the turbines on the flow. The model results in the following simple equation to determine the mean velocity at hub height inside the wind farm

$$
U_{h}=\frac{G}{1+\ln \left(\frac{G}{f \cdot h}\right) \frac{\sqrt{c_{t}+\left(\kappa / \ln \left(h / z_{0}\right)\right)^{2}}}{\kappa}} .
$$

Here $G$ denotes the geostrophic wind speed, $h$ is the hub height of the wind turbines, with all turbines assumed to be of equal size, and $f=2 \Omega \sin \varphi$ is the Coriolis parameter, in which $\Omega$ denotes the rotational speed of the earth, and $\varphi=$ $55^{\circ}$ (i.e. taken as the average latitude of the North Sea). The von Kármán constant is taken as $\kappa=0.4$, and $z_{o}$ is the surface roughness of the sea surface. The dimensionless parameter $c_{t}$ denotes the influence from the presence of the wind turbines on the deceleration of the wind speed inside the wind farm. This parameter is given by the following expression

$$
c_{t}=\frac{\pi C_{T}}{8 S^{2}}
$$

where $C_{T}$ is the thrust coefficient at which the wind turbine is operating, and $S=L / D$ denotes the dimensionless distance between the turbines, measured in turbine diameters, $D$.

In the following some of the parameters in the model will be simplified in order not to complicate the study unnecessarily. In general, the wind speed in the ABL depends on the vertical distance from the ground or sea surface, following the logarithmic law for neutral stability conditions. The parameters that govern the deceleration of the wind speed due to the presence of the turbines are, as can be seen from eq. (2), the density of the turbines, i.e. how close they are located from each other, and the axial load, i.e. the thrust coefficient. For simplicity, it is here assumed that the hub height is equal to the rotor diameter, and that the turbines operate close to the optimum, which here is taken as $C_{T}=0.8$. Furthermore, in the following the average undisturbed wind speed is taken as $9.7 \mathrm{~m} / \mathrm{s}$ at $100 \mathrm{~m}$ height, corresponding to 
Wind Energ. Sci. Discuss., https://doi.org/10.5194/wes-2018-53

Manuscript under review for journal Wind Energ. Sci.

Discussion started: 6 August 2018

(c) Author(s) 2018. CC BY 4.0 License.

103

104

105

106

107

108

109

110

111

a geostrophic wind speed of $12.2 \mathrm{~m} / \mathrm{s}$, and a roughness length at the sea surface $z_{o}=0.001 \mathrm{~m}$, numbers that are considered realistic for the North Sea (Penna and Hahmann, 2017 and Hahmann, 2017). By using eq. (1), the decelerated wind speed can be determined for different park turbine densities.

In general, the average distance between wind turbines in existing offshore wind farm corresponds to $6 \mathrm{D}-8 \mathrm{D}$. In some wind farms, however, such as the Swedish Lillgrund wind farm, the distance may be as low as 3.3D. The denser the turbines are located, the more the wind speed will be decelerated, which reduces the efficiency of the wind farm. On the other hand, a large distance between the turbines means a less total exploitation of the wind resource within the wind farm area. In the following analysis the distance between the turbines is taken as one of the two main variable parameters - the other being the turbine size.

\subsection{Average power production}

In order to determine the wind farm power production as well as to provide input to the applied cost model for wind farm operation and maintenance expenses, we need to estimate the ambient mean wind speed statistics as well as the associated wind farm mean wind speed statistics.

\subsection{Average production under ambient conditions}

Ambient wind speed statistics over the year (typically based on 10 minute or 30 minute averaging periods) are traditionally quantified using a two-parameter Weibull distribution. The probability density function (pfd) of a Weibull distributed random variable is

$$
f(x ; \lambda, k)= \begin{cases}\frac{k}{\lambda}\left(\frac{x}{\lambda}\right)^{k-1} e^{-\left(\frac{x}{\lambda}\right)^{k}} & ; x \geq 0 \\ 0 & ; x<0\end{cases}
$$

where $x$ is a realization of a stochastic variable $X, k>0$ is the Weibull shape parameter, and $\lambda>0$ is the Weibull scale parameter.

The power production of a solitary wind turbine, $P(U)$, at a given mean wind speed $U$ may, below rated wind speed $U_{r}$, be approximated by the following generic expression

$$
P(U)=\alpha U^{3}+\beta
$$

which obviously allows for zero turbine production at cut-in wind speed $U_{i n}$. Including this constraint in addition to the rated (installed) generator power $P_{r}$, with $U_{r}$ denoting the rated wind speed, the coefficients are determined as

$$
\alpha=\frac{P_{r}}{U_{r}^{3}-U_{i n}^{3}}, \quad \beta=-\frac{P_{r} U_{i n}^{3}}{U_{r}^{3}-U_{i n}^{3}},
$$

The definition of the power coefficient gives the following relation between rated power, rotor diameter, $D$, and rated wind speed,

$$
P_{r}=\frac{1}{8} \rho \pi D^{2} U_{r}^{3} C_{P, \text { rated }}
$$


Wind Energ. Sci. Discuss., https://doi.org/10.5194/wes-2018-53

Manuscript under review for journal Wind Energ. Sci.

Discussion started: 6 August 2018

(c) Author(s) 2018. CC BY 4.0 License.

with $\rho$ being the air density and $C_{P, \text { rated }}$ the rated power coefficient, which here is taken as 0.5 . We assume that the wind turbine operates at its optimum condition at wind speeds lower than the rated wind speed and at a constant power yield at wind speeds higher than the rated one. This is typical for a modern wind turbine, which is operated with variable tip speed at low wind speeds below the rated one, and which is pitch-regulated at higher wind speeds. With these assumptions the wind turbine power curve is given as

$$
P(U)= \begin{cases}\alpha U^{3}+\beta & ; \quad U_{\text {in }} \leq U<U_{r} \\ P_{r} & ; \quad U_{r} \leq U \leq U_{\text {out }}\end{cases}
$$

where the wind turbine cut-out wind speed is denoted as $U_{\text {out }}$. In the analysis it is assumed that $U_{\text {in }}=3 \mathrm{~m} / \mathrm{s}$ and $U_{\text {out }}=$ $25 \mathrm{~m} / \mathrm{s}$. The average production of the wind turbine, $P_{y}$, may be formulated as a convolution of the wind turbine production characteristics with the mean wind speed probability density function expressed in eq. (3). Thus

$$
\begin{aligned}
& P_{y}=\int_{U_{\text {in }}}^{U_{\text {out }}} P(U) f(U ; \lambda, k) d U \\
& =\alpha \int_{U_{\text {in }}}^{U_{r}} U^{3} f(U ; \lambda, k) d U+\beta \int_{U_{\text {in }}}^{U_{r}} f(U ; \lambda, k) d U+P_{r} \int_{U_{r}}^{U_{\text {out }}} f(U ; \lambda, k) d U
\end{aligned}
$$

Reformulating the Weibull distribution, eq. (3), as

$$
f(U ; \lambda, k)= \begin{cases}\frac{-d}{d(U)} e^{-\left(\frac{U}{\lambda}\right)^{k}} & ; x \geq 0 \\ 0 & ; x<0\end{cases}
$$

eq. (8) simplifies to

$$
P_{y}=\alpha \int_{U_{\text {in }}}^{U_{r}} U^{3} f(U ; \lambda, k) d U+\beta\left(e^{-\left(\frac{U_{\text {in }}}{\lambda}\right)^{k}}-e^{-\left(\frac{U_{r}}{\lambda}\right)^{k}}\right)+P_{r}\left(e^{-\left(\frac{U_{r}}{\lambda}\right)^{k}}-e^{-\left(\frac{U_{\text {out }}}{\lambda}\right)^{k}}\right) .
$$

The remaining integral in eq. (10) is solved using the variable transformation, $t=\left(\frac{U}{\lambda}\right)^{k}$, whereby we obtain

$$
\int_{U_{i n}}^{U_{r}} U^{3} f(U ; \lambda, k) d U=\lambda^{3} \int_{\left(U_{i n} / \lambda\right)^{k}}^{\left(U_{r} / \lambda\right)^{k}} t^{3 / k} e^{-t} d t=\lambda^{3}\left[\Gamma\left(\frac{3+k}{k},\left(\frac{U_{i n}}{\lambda}\right)^{k}\right)-\Gamma\left(\frac{3+k}{k},\left(\frac{U_{r}}{\lambda}\right)^{k}\right)\right],
$$

where $\Gamma\left({ }^{*}, *\right)$ is the Incomplete Gamma function (cf. Abramowitz and Stegun, 1970, p.260). Finally, introducing (11) in (10) we obtain the following closed form expression for the average wind turbine production 
Wind Energ. Sci. Discuss., https://doi.org/10.5194/wes-2018-53

Manuscript under review for journal Wind Energ. Sci.

Discussion started: 6 August 2018

(c) Author(s) 2018. CC BY 4.0 License.

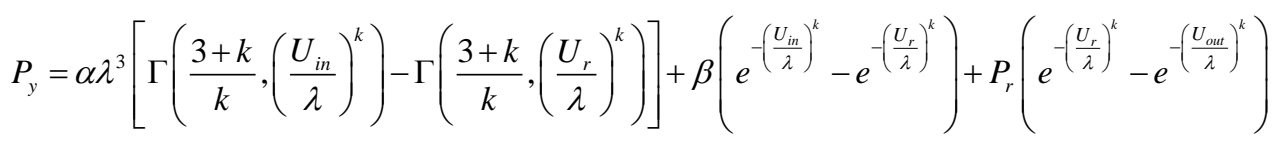

The Weibull parameters depend in general on altitude as well as on the stability conditions of the ABL. For the present North Sea study we simplify matters by assuming neutral ABL stability condition "in average", and under this assumption we conjecture that the Weibull shape parameter is independent of altitude. The mean of the Weibull distribution (i.e. the yearly mean wind speed), $\bar{U}_{y}$, may be expressed as

$$
\bar{U}_{y}=\lambda \Gamma(1+1 / k)
$$

where $\Gamma\left(^{*}\right)$ is the Gamma function. As seen, $\bar{U}_{y}$ scales directly with the Weibull scale parameter for a fixed shape parameter. As scale parameters we employ $\lambda=11 \mathrm{~m} / \mathrm{s}$ and $k=2.2$, corresponding to an average wind speed of $9.7 \mathrm{~m} / \mathrm{s}$, at a $100 \mathrm{~m}$ altitude. The numbers are taken as averaged values from measurements and simulations of selected locations in the North Sea (see Pena and Hahmann, 2017).

Discharging non-neutral atmospheric boundary layer stability conditions, a logarithmic shear profile may be assumed, meaning that the relative increase in mean wind speed, $f_{\Delta U}$, for an increase in altitude from a reference height $z_{r}$ to height $z$ is given by

$$
f_{\Delta U}=\bar{U} / \bar{U}_{r e f}=\operatorname{Ln}\left(z / z_{0}\right) / \operatorname{Ln}\left(z_{r e f} / z_{0}\right)
$$

with $z_{0}$ being the roughness length and $\bar{U}_{r e f}$ being the mean wind speed at the reference height.

The wind turbine capacity factor, $f_{C}$, expresses the ratio of the actual yearly output to its potential output, if it were possible to operate at full nameplate capacity continuously over the year. For the solitary turbine it is accordingly defined as

$$
f_{C}=P_{y} / P_{r}
$$

with $P_{y}$ obtained from eq. (12).

Assuming that the Weibull shape parameter is independent of altitude, the formulas for turbine average production (eq. (12)) and capacity factor (eq. (15)) apply for all altitudes, if the Weibull scale parameter, $\lambda$, associated with a reference height, is replaced with $f_{\Delta U} \lambda$ (cf. eq. (14)). In the above, the roughness length has implicitly been assumed constant, which strictly speaking is true only for an on-shore site. For offshore conditions the surface roughness depends on the wind speed, which complicates matters somewhat. However, this is disregarded in the present study.

\subsubsection{Average production under wind farm conditions}

The wind speed statistics inside a wind farm is different from the wind speed statistics of the ambient undisturbed flow discussed in the previous subsection. This is due to the wind speed reduction caused by the wind turbines, which, for a very large wind farm, may be estimated according to eq. (1). In this subsection, we will derive the distribution of the mean wind speed at hub height inside an "infinite" wind farm and in turn estimate the average power production of turbines 
Wind Energ. Sci. Discuss., https://doi.org/10.5194/wes-2018-53

Manuscript under review for journal Wind Energ. Sci.

Discussion started: 6 August 2018

(c) Author(s) 2018. CC BY 4.0 License.

192

193

194

195

196

197

198

199

200

201

202

203

or

$$
U_{H, 0}=\frac{G}{1+\ln \left(\frac{G}{f h_{H}}\right) \frac{1}{\ln \left(h_{H} / z_{0}\right)}} .
$$

We introduce the following short hand notation

$$
\gamma=\ln \left(\frac{G}{f h_{H}}\right), \quad \delta=\ln \left(\frac{h_{H}}{z_{0}}\right)
$$

whereby

$$
U_{H}\left[1+\gamma \frac{\sqrt{c_{t}+(\kappa / \delta)^{2}}}{\kappa}\right]=U_{H, 0}\left[1+\frac{\gamma}{\delta}\right],
$$

The thrust coefficient $C_{T}$ is approximated as

$$
U_{H}=U_{H, 0} \frac{1+\frac{\gamma}{\delta}}{1+\gamma \frac{\sqrt{c_{t}+(\kappa / \delta)^{2}}}{\kappa}} .
$$

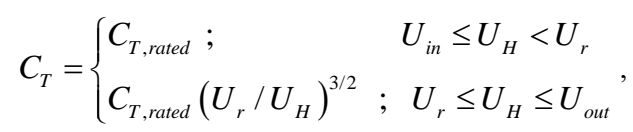


Wind Energ. Sci. Discuss., https://doi.org/10.5194/wes-2018-53

Manuscript under review for journal Wind Energ. Sci.

Discussion started: 6 August 2018

(c) Author(s) 2018. CC BY 4.0 License.

where $C_{T, \text { rated }}$ is the rated thrust coefficient, which in the following is taken as 0.8 , and $U_{r}$ is the rated wind speed. Introducing eq. (2) into eq. (20) one obtains

$$
\frac{U_{H}}{U_{H, 0}}=\left\{\begin{array}{ll}
\varepsilon_{1}=\frac{1+\frac{\gamma}{\delta}}{1+\frac{\gamma}{\kappa} \sqrt{\frac{\pi C_{T, \text { rated }}}{8 S^{2}}+(\kappa / \delta)^{2}}} ; & U_{\text {in }} \leq U_{H}<U_{r} \\
\varepsilon_{2}=\frac{\gamma}{1+\frac{\gamma}{\delta} \sqrt{\frac{\pi C_{T, \text { rated }}}{8 S^{2}}\left(U_{r} / U_{H}\right)^{3 / 2}+(\kappa / \delta)^{2}}} ; & U_{r} \leq U_{H} \leq U_{\text {out }}
\end{array} .\right.
$$

As seen from eq. (22), $\varepsilon_{1}$ is a constant whereas $\varepsilon_{2}=\varepsilon_{2}\left(U_{H}\right)$ depends on the actual velocity at hub height.

To determine the probability density function for the wind farm, we exploit the following relationship between the original Weibull distribution, $f_{H, 0}$, and the altered distribution, $f_{H}$, due to the wake effects from the wind turbines in the farm,

The probability density function of $U_{H}$ in the below rated regime can now be formulated in closed form by combining eq. (22) and eq. (23),

$$
f_{H}\left(U_{H}\right) d U_{H}=f_{H, 0}\left(U_{H, 0}\right) d U_{H, 0} .
$$

$$
\text { It is intuitively clear that, with the wind speed transformation expressed in (22) for the below rated regime, an infinitesimal }
$$
probability around $U_{H, 0}$ for the ambient conditions, equals an infinitesimal probability around $U_{H}$ for the infinite wind farm conditions, which is exactly what is expressed in eq. (24). As in section 2.2.1, we assume the ambient mean wind speeds to be Weibull distributed (cf. eq. (3)), whereby we finally obtain the following mean wind speed probability density function for the below rated wind farm wind climate,

$$
f_{H}\left(U_{H}\right)=f_{H, 0}\left(U_{H} ; \varepsilon_{1} \lambda, k\right) ; \quad U_{i n} \leq U_{H}<U_{r}
$$

which is a Weibull distributed mean wind speeds with scale parameter $\varepsilon_{1} \lambda>0$.

We now turn to the above rated wind farm regime. Assuming again that the mean wind speed in the ambient domain is Weibull distributed, the expected yearly wind turbine production for the above rated wind farm wind speed regime may 
Wind Energ. Sci. Discuss., https://doi.org/10.5194/wes-2018-53

Manuscript under review for journal Wind Energ. Sci.

Discussion started: 6 August 2018

(c) Author(s) 2018. CC BY 4.0 License.

be formulated as

(1)

$P_{r} \int_{U_{r}}^{U_{\text {out }}} f_{H}\left(U_{H}\right) d U_{H}=P_{r} \int_{U_{r} / \varepsilon_{2}\left(U_{r}\right)}^{U_{\text {out }} / \varepsilon_{2}\left(U_{\text {out }}\right)} f_{H, 0}\left(U_{H, 0} ; \lambda, k\right) d U_{H, 0}$.

or, using eq. (10)

$$
P_{r} \int_{U_{r}}^{U_{H, o}} f_{H}\left(U_{H}\right) d U_{H}=P_{r}\left(e^{-\left(\frac{U_{r}}{\varepsilon_{2}\left(U_{r}\right) \lambda}\right)^{k}}-e^{-\left(\frac{U_{\text {out }}}{\varepsilon_{2}\left(U_{\text {out }}\right) \lambda}\right)^{k}}\right)
$$

We are now ready to compute the yearly output of a wind farm turbine, which then in turn is used to determine the wind farm capacity factor defined in eq. (15). Employing eq. (27), and otherwise taking a similar approach as the one leading to eq. (12) for a solitary turbine, the yearly power output is determined as

$$
P_{W F, y}=\int_{U_{\text {in }}}^{U_{\text {out }}} P\left(U_{H}\right) f_{H}\left(U_{H} ; \varepsilon \lambda, k\right) d U_{H}
$$

$$
=\alpha \int_{U_{\text {in }}}^{U_{r}} U_{H}^{3} f_{H}\left(U_{H} ; \varepsilon_{1} \lambda, k\right) d U_{H}+\beta \int_{U_{\text {in }}}^{U_{r}} f_{H}\left(U_{H} ; \varepsilon_{1} \lambda, k\right) d U_{H}+P_{r}\left(e^{-\left(\frac{U_{r}}{\varepsilon_{2}\left(U_{r}\right) \lambda}\right)^{k}}-e^{-\left(\frac{U_{\text {out }}}{\varepsilon_{2}\left(U_{\text {out }}\right) \lambda}\right)^{k}}\right) \cdot
$$

The first two terms in eq. (28) can be determined analytically, in analogy with the derivation leading to eq. (12), and we thus finally obtain the following closed form expression for the average annual power output of a wind farm turbine,

$$
P_{W F, y}=\alpha\left(\varepsilon_{1} \lambda\right)^{3}\left[\Gamma\left(\frac{3+k}{k},\left(\frac{U_{i n}}{\varepsilon_{1} \lambda}\right)^{k}\right)-\Gamma\left(\frac{3+k}{k},\left(\frac{U_{r}}{\varepsilon_{1} \lambda}\right)^{k}\right)\right]+\beta\left(e^{-\left(\frac{U_{i n}}{\varepsilon_{1} \lambda}\right)^{k}}-e^{-\left(\frac{U_{r}}{\varepsilon_{1} \lambda}\right)^{k}}\right)
$$

$$
+\quad P_{r}\left(e^{-\left(\frac{U_{r}}{\varepsilon_{2}\left(U_{r}\right) \lambda}\right)^{k}}-e^{-\left(\frac{U_{\text {out }}}{\varepsilon_{2}\left(U_{\text {out }}\right) \lambda}\right)^{k}}\right)
$$

Essentially, it is only allowed to exploit eqs. (23) and (24) if it can be proved that there exists a one-to-one transformation between $f_{H}$ and $f_{H, 0}$. A way to prove this is to demonstrate that $U_{H}=U_{H}\left(U_{H, 0}\right)$ is a monotonic function. For the below rated wind speed case this is easily shown as $\varepsilon_{1}$ in eq. (22) is a constant. For the above rated wind speed case a formal proof is given in App. A.

\subsection{Wind farm layout characteristics}

The specific wind farm topology assumed for the present study is the simplest possible; i.e. a quadratic grid with the wind turbines uniformly interspaced in two perpendicular horizontal directions. Hence, assuming a total number of wind turbines, $N_{T}$, located at a distance, $L$, from each other, the side length of the quadratic wind farm grid is given as $L\left(\sqrt{N_{T}}-1\right)$. With this assumption, the required area, $A$, relates to the number of turbines as 
Wind Energ. Sci. Discuss., https://doi.org/10.5194/wes-2018-53

Manuscript under review for journal Wind Energ. Sci.

Discussion started: 6 August 2018

(c) Author(s) 2018. CC BY 4.0 License.

$$
A=\left[L\left(\sqrt{N_{T}}-1\right)\right]^{2}=S^{2} D^{2}\left(\sqrt{N_{T}}-1\right)^{2},
$$

273

274

275

276

278

Where $S$ is the wind turbine interspacing in rotor diameters, $D$. For a given area the number of turbines is from eq. (30) determined as

7

$$
N_{T}=\left[\frac{\sqrt{A}}{S_{L} D}+1\right]^{2}
$$

To determine the installed capacity we will need a relationship between the turbine rated power, $P_{r}$, and the rotor diameter. This is obtained by assessing eq. (6) at rated wind speed,

$$
P_{r}=K \cdot D^{2}
$$

where

$$
K=\frac{\pi}{8} \rho U_{r}^{3} C_{P, \text { rated }} .
$$

Combining eqs. (30) and (32), we get the following expression for the power area density (i.e. the installed capacity per area unit)

$$
\frac{N_{T} P_{r}}{A}=\frac{N_{T} K}{S^{2}\left(\sqrt{N_{T}}-1\right)^{2}} .
$$

\subsection{Bathymetry of the North Sea}

The North Sea is nearly $1000 \mathrm{~km}$ long and $600 \mathrm{~km}$ wide, with a total area of around $570.000 \mathrm{~km}^{2}$. Most of the North Sea is on the European Continental shelf and has an average depth of about $90 \mathrm{~m}$. In the southern part the water is very shallow, with average water depths of 25 to $35 \mathrm{~m}$, increasing to depths up to between 100 and $200 \mathrm{~m}$ north of the Shetland Islands. In the south, the depth is at most $50 \mathrm{~m}$, and a large part of it is the sand bank Dogger Bank, which has water depth of about $25 \mathrm{~m}$. Therefore, the southern part of the North Sea is ideal for erecting wind turbines.

\section{Depth profile}

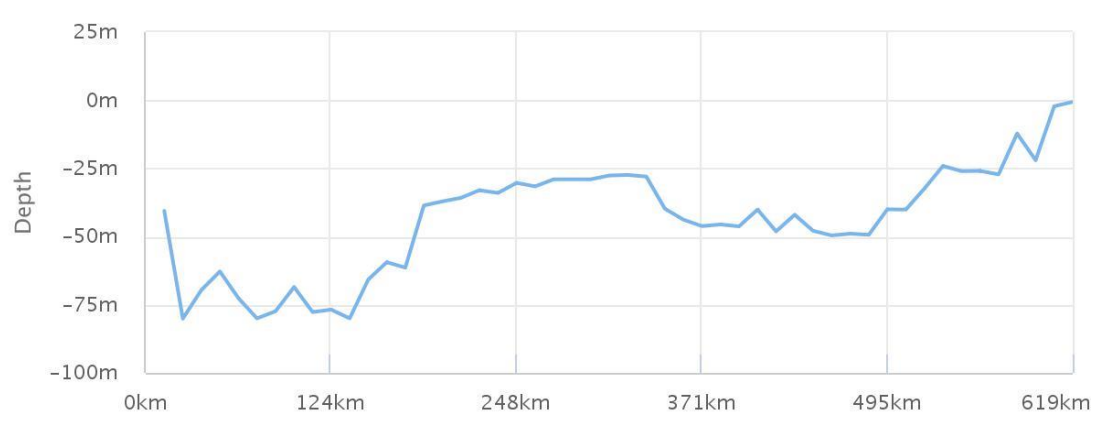

Figure 2: Depth profile of a line spanning from New Castle (UK) to Hanstholm (DK). 
Wind Energ. Sci. Discuss., https://doi.org/10.5194/wes-2018-53

Manuscript under review for journal Wind Energ. Sci.

Discussion started: 6 August 2018

(c) Author(s) 2018. CC BY 4.0 License.

The bathymetric properties of the North Sea can be determined by inspection of the European Marine Observation and Data Network (EMODnet, 2017). An example of this is shown in Fig. 2, where the water depth has been extracted along a line going from the east coast of U.K (New Castle) to the west coast of Denmark (Hanstholm). As seen on the plot a large part is covered by a shallow plane, which is the Dogger Bank. By systematically extracting data from this website it has been made possible to generate the full bathymetric properties of the North Sea (Nielsen, 2015). This is shown in Figs. 3 and 4, which depict the distribution of area (Fig. 3) and the accumulated area (Fig. 4) as function of water depth. From these figures it is seen that about $250.000 \mathrm{~km}^{2}$ of the sea has water depths less than $60 \mathrm{~m}$, which makes this part ideal for erecting wind turbines on monopoles or jacket substructures. A full mapping of the water depth is important for the subsequent economic analysis, as the cost of wind turbine substructures depends heavily on water depth.

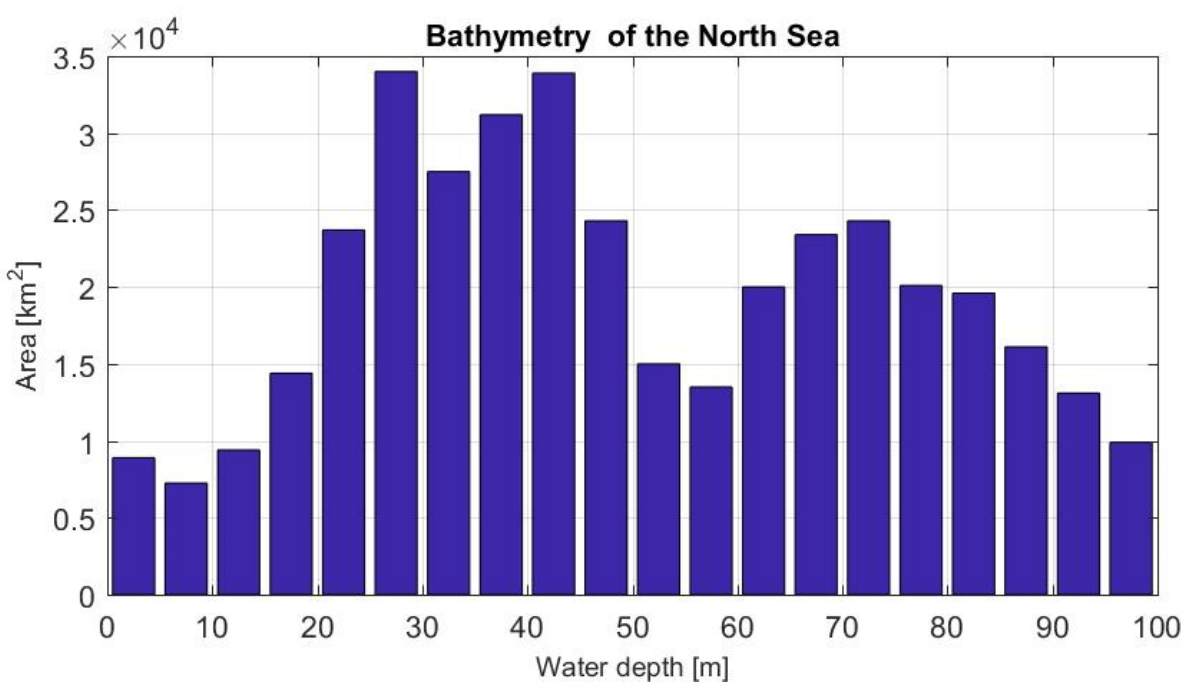

Figure 3: Bar diagram showing areas with specific water depths.

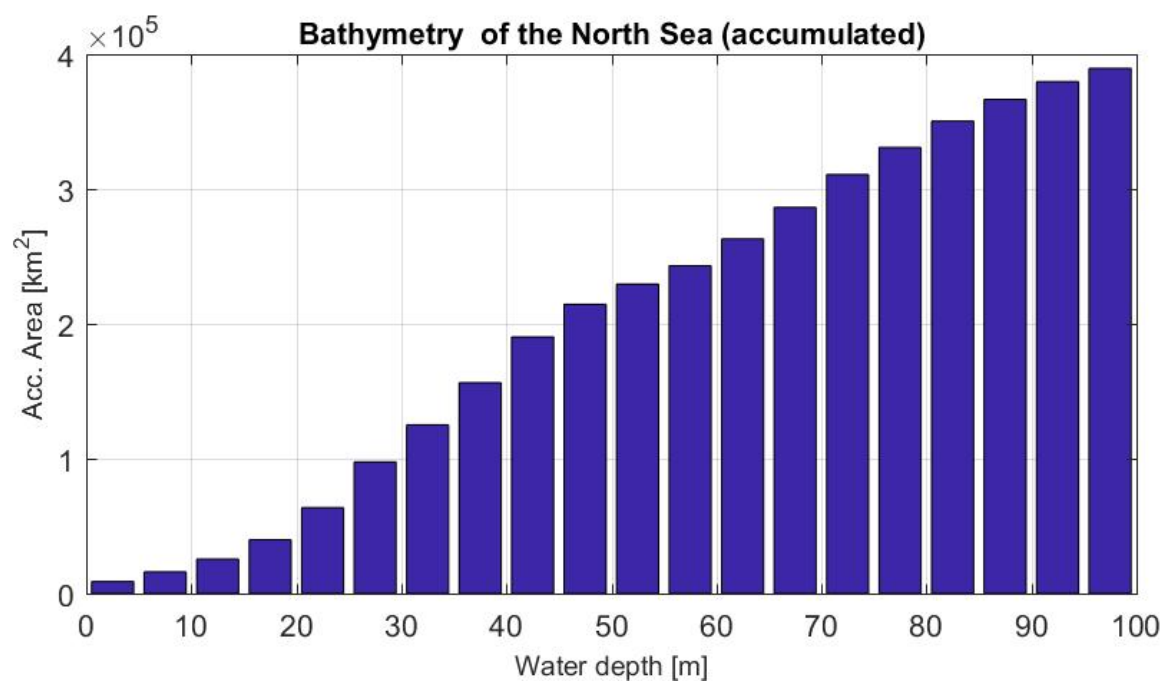

Figure 4: Accumulated area as function of increasing water depth. 
Wind Energ. Sci. Discuss., https://doi.org/10.5194/wes-2018-53

Manuscript under review for journal Wind Energ. Sci.

Discussion started: 6 August 2018

(c) Author(s) 2018. CC BY 4.0 License.

\subsection{Cost models}

Cost models are needed for any economic optimization aiming at finding the optimal balance between wind turbine production, operational costs and financial costs. Given the broad and generic character of the present study, relatively simple models have been used. These, as well as the assumptions on which they are based, are described in the following.

\subsubsection{Cost of wind turbine}

The cost of a wind turbine in $\mathrm{M} €, C_{W T}$, may according to Lundberg (2003) be taken as $C_{W T}=-0.15+0.92 P_{R}$, where $P_{R}$ is the installed generator power in MW. However, this pricing refers to the year 2003, where the report was compiled. The inflationary development in (Danish) consumer prices in general from 2003 and up to the year 2015 is 23\% (Retail prices index, 2015). In this study we will assume wind turbine prices to follow the inflation in general consumer prices during this period, and we will further add $2 \%$ to approximately include the wind turbine price development up to today (i.e. 2017). With these assumptions we finally arrive at the following expression for wind turbine prices in M€

$$
C_{W T}=1.25\left(-0.15+0.92 P_{R}\right) .
$$

\subsubsection{Cost of support structure}

Cost and type of wind turbine support structures depend primarily on wind turbine size and water depth. A monopole foundation is considered advantageous for shallow water regimes, which in the present context means water depths up to about $35 \mathrm{~m}$. For water depths beyond $35 \mathrm{~m}$ jacket foundations are convenient and consequently assumed.

The cost of a monopile support structure in $\mathrm{M} €, C_{F M}$, may in a first order approximation be simplified as (Buhl and Natarajan, 2015)

$$
C_{F M}=\frac{P_{R}\left(H^{2}+100 H+1500\right)}{7500},
$$

where $P_{R}$ denotes the wind turbine rated power in MW, and $H$ is the water depth in meters.

Cost of a jacket support structure in $\mathrm{M} €, C_{F J}$, may in a first order approximation be simplified as (Buhl and Natarajan, 2015)

$$
C_{F J}=\frac{P_{R}\left(4.5 H^{2}-35 H+2500\right)}{7500} .
$$

\subsubsection{Cost of wind farm electrical grid}

Assuming the internal electrical grid predominantly (i.e. except for one connecting line along the alternative direction) laid out along one of the directions in the quadratic grid, the aggregated length of the grid cables, $L_{C}$, is given by

$$
L_{C}=S D\left(\sqrt{N_{T}}+1\right)\left(\sqrt{N_{T}}-1\right)=S D\left(N_{T}-1\right) .
$$


Wind Energ. Sci. Discuss., https://doi.org/10.5194/wes-2018-53

Manuscript under review for journal Wind Energ. Sci.

Discussion started: 6 August 2018

(c) Author(s) 2018. CC BY 4.0 License.

The wind farm grid financial costs pr. running meter, including cable cost and costs of installation, for an offshore site is taken as $C_{C}=675 €$ (Rethoré et al., 2014 and Larsen et al., 2011). Consequently, the total aggregated grid costs, $C_{G}$, are given as

$$
C_{G}=L_{C} C_{C}
$$

\subsubsection{Cost of operation and maintenance}

Cost of operation and maintenance $(\mathrm{O} \& \mathrm{M}), C_{O \& M}$, depends on turbine size as well as on wind turbine spacing, in the sense that a smaller spacing, and thereby higher loadings, increases the costs and, for larger turbines, these costs are reduced per installed MW. It is reasonable to assume that the relative wind turbine size effect (e.g. the relative reduction in O\&M for one 6MW wind turbine compared to two $3 \mathrm{MW}$ WT's) for wind turbines subjected to identical load conditions is independent of the particular load level, and we will consequently assume that the size and load dependencies can be factorized as

$$
C_{O \& M}\left(P_{R}, S\right)=f_{W T}\left(P_{R} \mid P_{R, R e f}\right) \cdot C_{W T_{R e f}} \cdot f_{C} \cdot f_{S}(S)
$$

where $f_{W T}\left(P_{R} \mid P_{R, R e f}\right)$ is the wind turbine size factor, $C_{W T_{R e f}}$ is the yearly cost of O\&M for a reference turbine with rated power, $P_{R, R e f}$, operating under ideal conditions with a wind turbine capacity factor equal to one, $f_{C}$ is the wind turbine capacity factor for an imaginary solitary wind turbine at the site of interest, and $f_{S}(S)$ is a load factor accounting for the impact of the wind farm load level, and thus of the wind turbine spacing, on the O\&M costs. The load factor depends on the load condition for the particular wind farm turbine, and it is expressed in terms of wind farm topology (i.e. spacing) as

$$
f_{S}(S)=\frac{P_{S, y}}{P_{W F, y}}=\left(\frac{P_{S, y}}{P_{r}}\right) /\left(\frac{P_{W F, y}}{P_{r}}\right)=\frac{f_{C}}{f_{W F}},
$$

where $P_{S, y}$ is the average annual power yield of a solitary turbine at the site of interest, $P_{W F, y}$ is the average annual power yield of a wind farm turbine and $f_{W F}=P_{W F, y} / P_{r}$ is the wind farm capacity factor. As seen, the load factor increases for decreasing wind farm capacity factor (and vice versa) reflecting increased wake impact and thus in turn increased loading. Inspired by Berger (2013), where a 14\% reduction of annual OPEX cost per MW is stated by shifting from $3 \mathrm{MW}$ to $6 \mathrm{MW}$ turbines, we will assume that this relative reduction can be linearly extrapolated to other WT sizes within the a size regime spanned by half and double the size of the reference wind turbine, respectively. Outside this size regime it seems reasonable to assume an exponential behavior, where $14 \%$ reduction of OPEX is gained for a doubling of wind turbine size, and a corresponding increase of OPEX results if the wind turbine size is halved. Thus, for an increase in wind turbine size 
Wind Energ. Sci. Discuss., https://doi.org/10.5194/wes-2018-53

Manuscript under review for journal Wind Energ. Sci.

Discussion started: 6 August 2018

(c) Author(s) 2018. CC BY 4.0 License.

$$
f_{W T}\left(P_{R} \mid P_{R, R e f}\right)=\left\{\begin{array}{cl}
1-\frac{0.14\left(P_{R}-P_{R, R e f}\right)}{P_{R, R e f}} & \text { for } P_{R, R e f} \leq P_{R} \leq 2 P_{R, R e f} \\
0.86^{0.5 P_{R} / P_{R, R e f}} & \text { for } 2 P_{R, R e f}<P_{R}
\end{array} .\right.
$$

379

380 381

For a decrease in WT size the analog expression is

$$
f_{W T}\left(P_{R} \mid P_{R, R e f}\right)=\left\{\begin{array}{cc}
1-\frac{0.325\left(P_{R}-P_{R, R e f}\right)}{P_{R, R e f}} & \text { for } 0.5 P_{R, R e f} \leq P_{R} \leq P_{R, R e f} \\
0.86^{-0.5 P_{R, R e f} / P_{R}} & \text { for } P_{R}<0.5 P_{R, R e f}
\end{array} .\right.
$$

Note, that the difference in factors in the linear expressions relates to the reference turbine being the smallest respectively the largest turbine in these expressions.

The reference turbine is for the present study taken as a 10MW turbine, for which the O\&M costs per year may be specified as $C_{W T, R e f}=106 € / \mathrm{kW}$ (Chaviaropoulos and Natarajan, 2014).

Because O\&M costs are running costs, contrary to the financial costs described in sections 2.5.1 - 2.5.3, which refer to the time of the wind farm installation, we need assumptions on the development of O\&M costs over time in comparison with the inflation. We will here assume that the development of O\&M costs over time follows the inflation in general. This makes the rate of inflation the natural choice for the discounting rate, and with this choice we conveniently avoid computation of net present values by letting all prices referring to the time of wind farm installation (Larsen, 2009).

\subsubsection{Levelized cost of energy}

Other costs than those described in the previous sections - e.g. cost of transformer station(s) and establishment of a main cable to the coast - are presumed to depend only on the rated production of the wind farm and thus for the present study independent of the wind farm layout (i.e. wind turbine spacing) and the choice of turbine size. Consequently, this cost can in principle be omitted for the present layout cost optimization considerations. However, such costs will of cause affect the levelized cost of energy (LCoE) estimate, and to arrive at reasonable realistic LCoE estimates we will, in line with Mahulja (2015), assume that cost of WT's, internal WF grid and foundations accounts for $75 \%$ of the total investment costs, which is based on experiences from the Danish Horns Rev and Nysted offshore wind farms. The remaining $25 \%$ is mainly due to electrical infrastructures, such as onshore cables and substations. The estimated LCoE expressed in terms of a $\mathrm{kW}$ price is consequently given by

$$
L C o E=1.33 \frac{N_{T}\left[C_{W T}+N_{Y} P_{E} C_{O \& M} / 1.33+\gamma C_{F M}+(1-\gamma) C_{F J}\right]+C_{G}}{N_{Y} P_{E}},
$$

where $\gamma$ is the fraction of wind turbines erected on monopole foundations, $(1-\gamma)$ is the fraction of wind turbines erected on jacket foundations, $N_{Y}$ is the life time of the wind farm in years, and $P_{E}$ is the yearly consumption of electricity in $\mathrm{kW}$. For the present study we will assume a wind farm life time of 20 years; i.e. $N_{Y}=20$. 
Wind Energ. Sci. Discuss., https://doi.org/10.5194/wes-2018-53

Manuscript under review for journal Wind Energ. Sci.

Discussion started: 6 August 2018

(c) Author(s) 2018. CC BY 4.0 License.

409

\section{Results}

As mentioned previously, the results include an investigation of the dependence of wind turbine size and interspacing on power density, as well as an analysis to determine the optimal wind turbine size and interspacing (i.e. wind farm topology) from an economic perspective. The economic model is formulated using a simple design space spanned by only two discrete optimization parameters, namely the mutual distance between the turbines, $S$, and the turbine size, D, which here is limited to take the values $100 \mathrm{~m}, 150 \mathrm{~m}, 200 \mathrm{~m}$ and $250 \mathrm{~m}$. From eq. (6), assuming a rated wind speed $U_{r}=11 \mathrm{~m} / \mathrm{s}$, the turbine sizes are determined to correspond to an installed power of 3.2 MW, 7.3 MW, $13 \mathrm{MW}$ and $20 \mathrm{MW}$, respectively.

\subsection{Power density and area requirements}

As a first part of the study we here analyze the power density of the wind resources in the North Sea and assess the area required to cover the power demand of Europe as per 2016. By solving the system of equations outlined in sections 2.12.3 , the power density, i.e. the power production per unit area sea surface, may be obtained as a function of wind turbine spacing and rotor diameter. The outcome of this is shown in Fig. 5, which depicts the power density as a function of rotor spacing, $S$, spanning the range from 4 diameters to 11 diameters, and for the above mentioned four different rotor diameters. In this range it is seen that the power density decreases monotonically from about $4.5 \mathrm{~W} / \mathrm{m}^{2}$ at $S=4$ to about $1 \mathrm{~W} / \mathrm{m}^{2}$ at $S=11$. It should be noted that the power density attains a maximum at a rotor spacing of about $1.5 \mathrm{D}-2 \mathrm{D}$, which, depending of rotor size, goes from $4 \mathrm{~W} / \mathrm{m}^{2}$ for $\mathrm{D}=100 \mathrm{~m}$ to $7.5 \mathrm{~W} / \mathrm{m}^{2}$ for $\mathrm{D}=200 \mathrm{~m}$. For a 'standard' value of $S$ $=7$ and $\mathrm{D}=150 \mathrm{~m}$, we get a power intensity of about $2 \mathrm{~W} / \mathrm{m}^{2}$. For a comparison, in a similar study by Frandsen et al. (2009), the power density was found to vary in the range form $1.9 \mathrm{~W} / \mathrm{m}^{2}$ to $4 \mathrm{~W} / \mathrm{m}^{2}$, depending on rotor size and spacing.

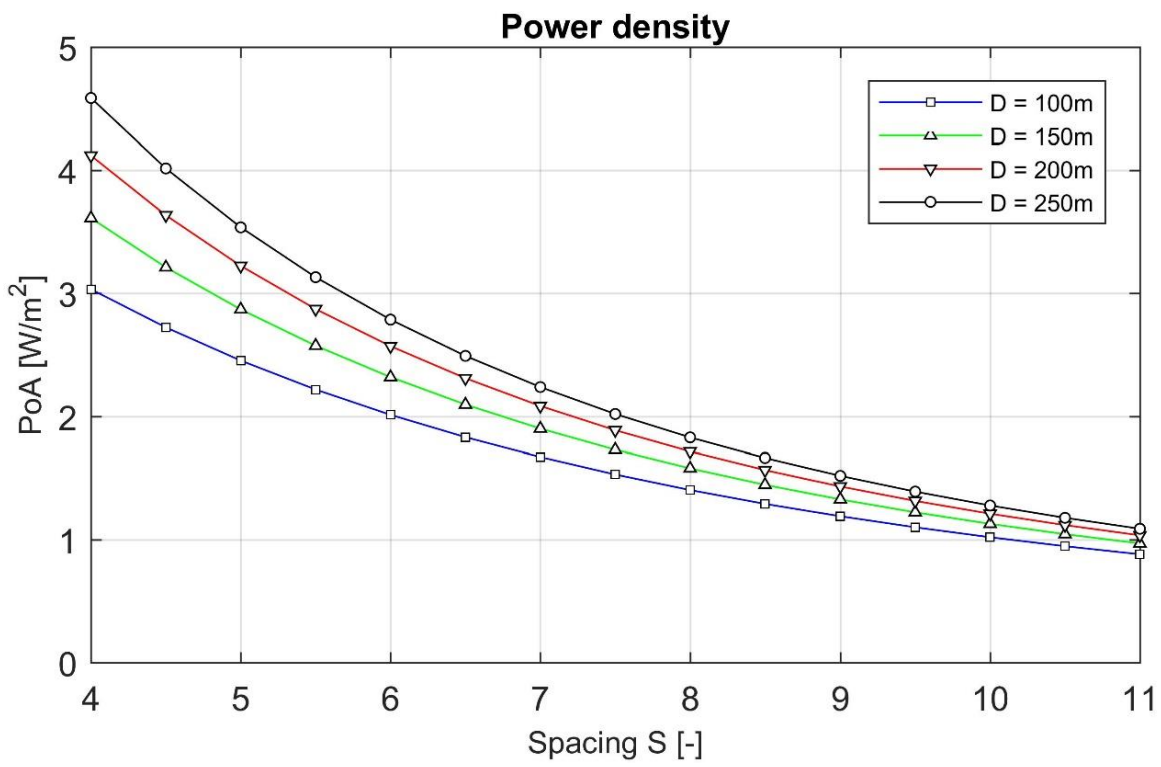

Figure 5: Power density as function of spacing and rotor diameter.

For existing wind farms, such as the Danish Nysted or Horns Rev wind farms, the power intensity is measured to range from $2.7 \mathrm{~W} / \mathrm{m}^{2}$ to $4 \mathrm{~W} / \mathrm{m}^{2}$ (Frandsen et al., 2009 and Volker, 2015). The corresponding capacity factor is in Fig. 6 seen to vary from about 0.15 to 0.4 , again depending on turbine distance and diameter. 
Wind Energ. Sci. Discuss., https://doi.org/10.5194/wes-2018-53

Manuscript under review for journal Wind Energ. Sci.

Discussion started: 6 August 2018

(c) Author(s) 2018. CC BY 4.0 License.

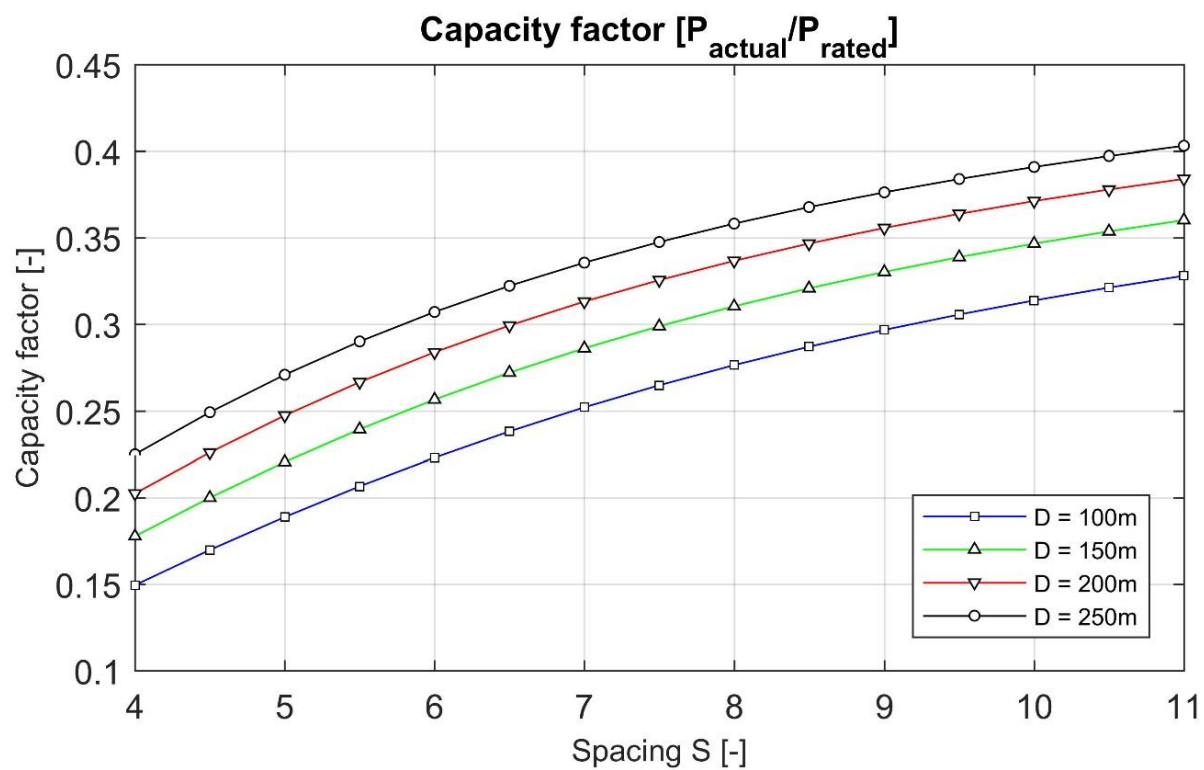

Figure 6: Capacity factor as function of spacing and rotor diameter.

The energy production in various parts of the North Sea is obtained by combining the bathymetry with the actual annual energy production per area unit for a given combination of rotor size and interspacing. As an example, assuming a rotor diameter $\mathrm{D}=200 \mathrm{~m}$ and a spacing $S=7$, we get an energy production on different water depths as shown in Fig. 7. Essentially Fig. 7 is obtained by multiplying the values in Fig. 3 by the annual energy production per square kilometer, as the energy production does not depend on the water depth.

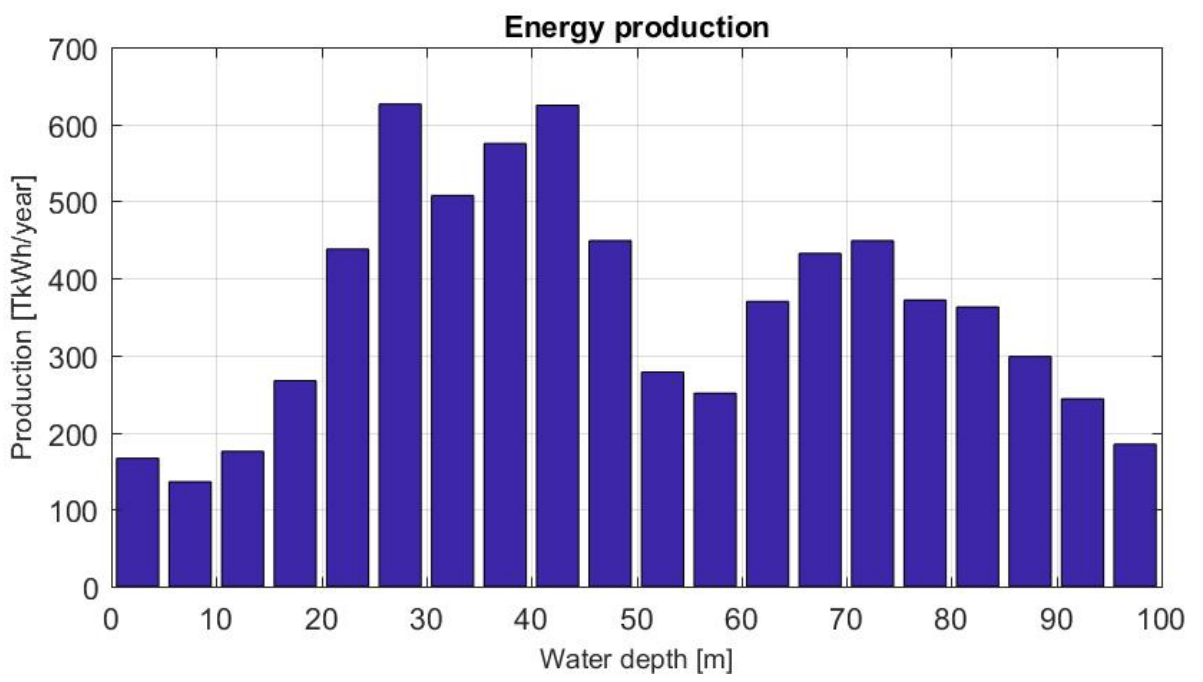

Figure 7: Energy production as function of water depth for $D=200 \mathrm{~m}$ and $S=7$.

The accumulated energy production on water depths is shown in Fig.8, which essentially is identical to Fig. 4, except for a scaling of the ordinate. From the two figures it is seen, that most energy production in fact can be obtained 
Wind Energ. Sci. Discuss., https://doi.org/10.5194/wes-2018-53

Manuscript under review for journal Wind Energ. Sci.

Discussion started: 6 August 2018

(c) Author(s) 2018. CC BY 4.0 License.

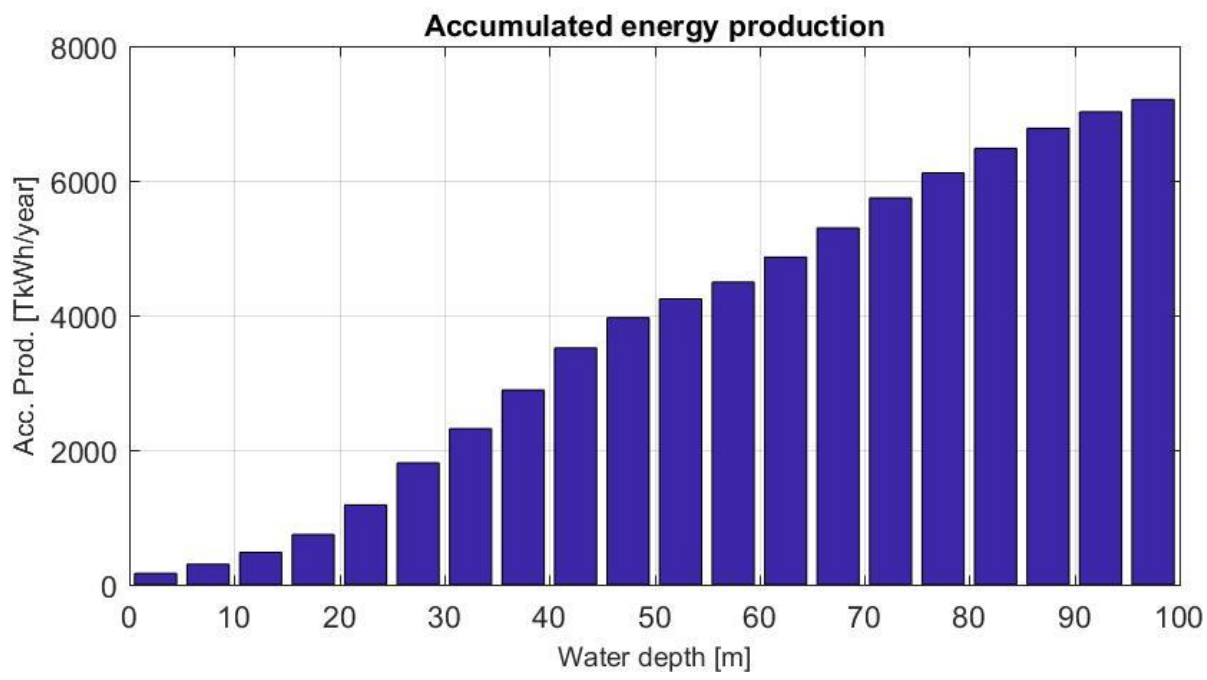

Figure 8: Accumulated energy production as function of water depth for $D=200 \mathrm{~m}$ and $S=7$.

Referring to the year 2016, the power demand for Europe is about $0.4 \mathrm{TW}$, corresponding to a production of about $3500 \mathrm{TWh} /$ year (Eurostat Statistics Explained, 2016 and Electricity in Europe, 2013). Fig. 9 shows the area required to provide the power demand for Europe as a function of wind turbine spacing and rotor diameter. For the chosen parameter values, the required area is seen to be in the range from about $100.000 \mathrm{~km}^{2}$ to about $450.000 \mathrm{~km}^{2}$. For a foreseeable 460

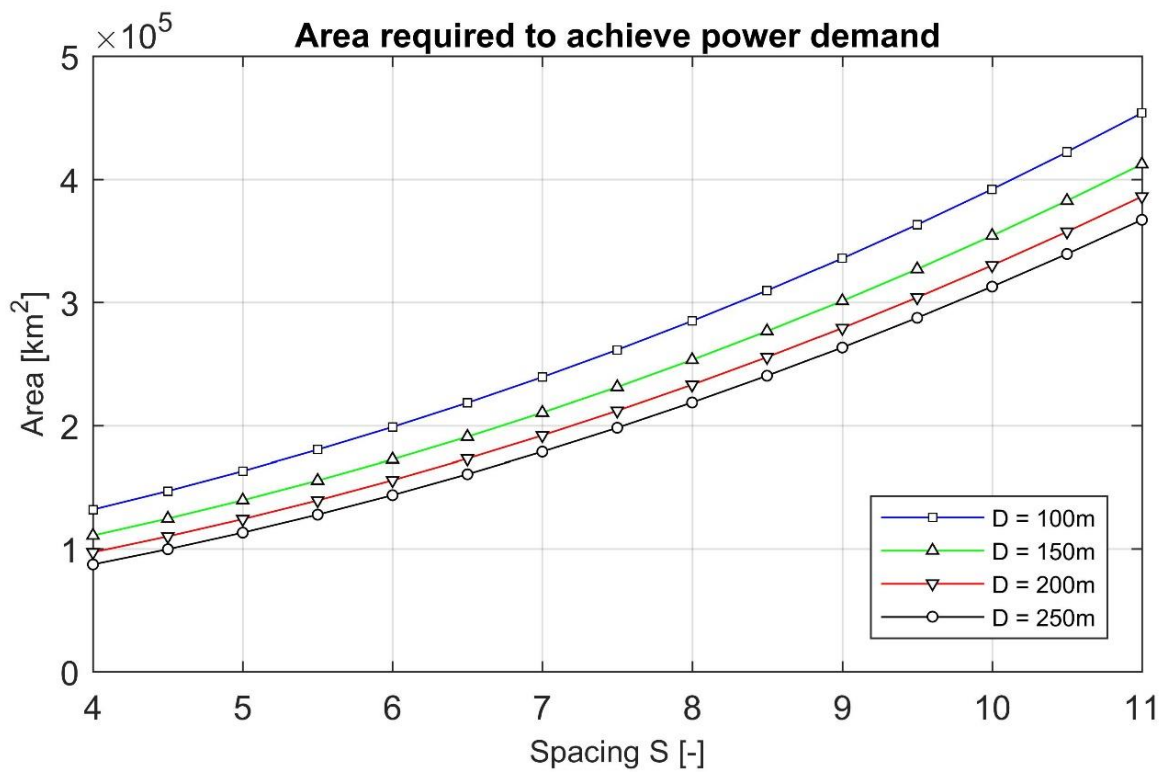

Figure 9: Area required to produce Europe's power demand as function of spacing and rotor diameter. 
Wind Energ. Sci. Discuss., https://doi.org/10.5194/wes-2018-53

Manuscript under review for journal Wind Energ. Sci.

Discussion started: 6 August 2018

(c) Author(s) 2018. CC BY 4.0 License.

463

464

465

466

to $1 / 3$ of the area of the North Sea and, as seen from Fig. 8 , this target can be achieved by exploiting water depths less than $45 \mathrm{~m}$. The required installed power and number of turbines are depicted in Figs. 10 and 11, respectively. For the 'standard' configuration it is required to install about $100.00013 \mathrm{MW}$ wind turbines, corresponding to an installed power capacity of about $1.25 \mathrm{TW}$.

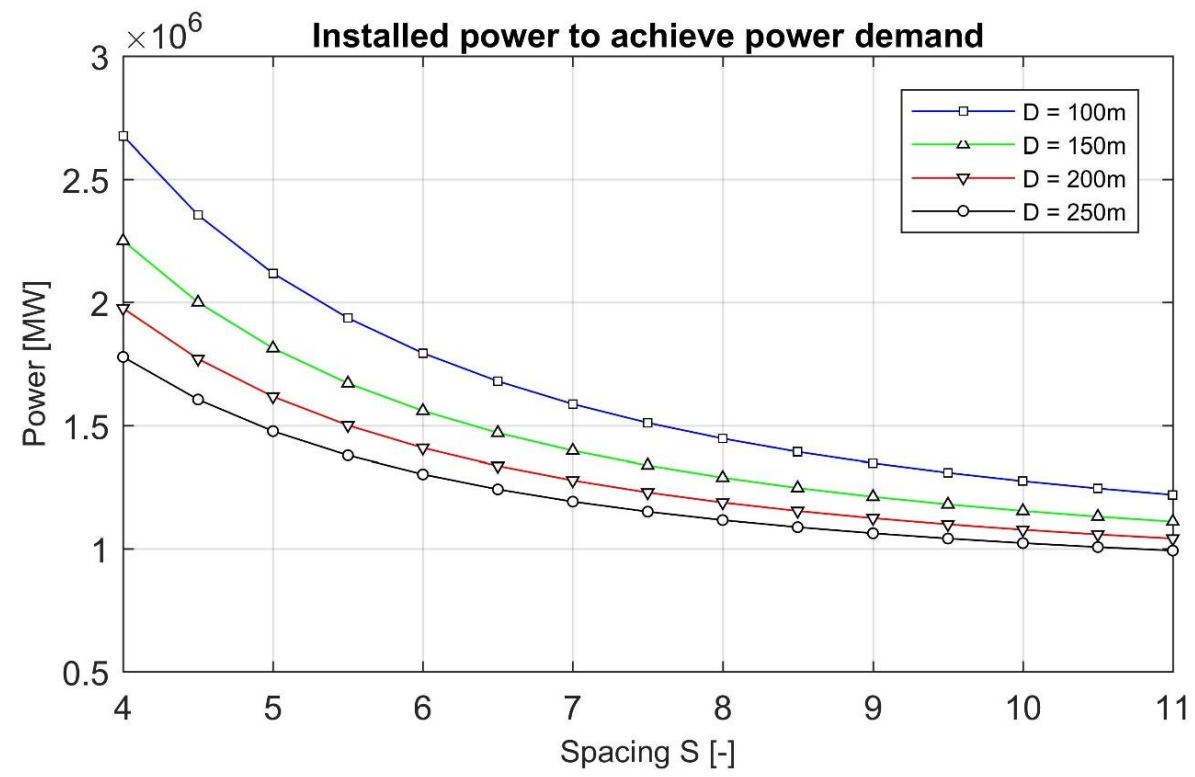

Figure 10: Installed power required to produce Europe's power demand as function of spacing and rotor diameter.

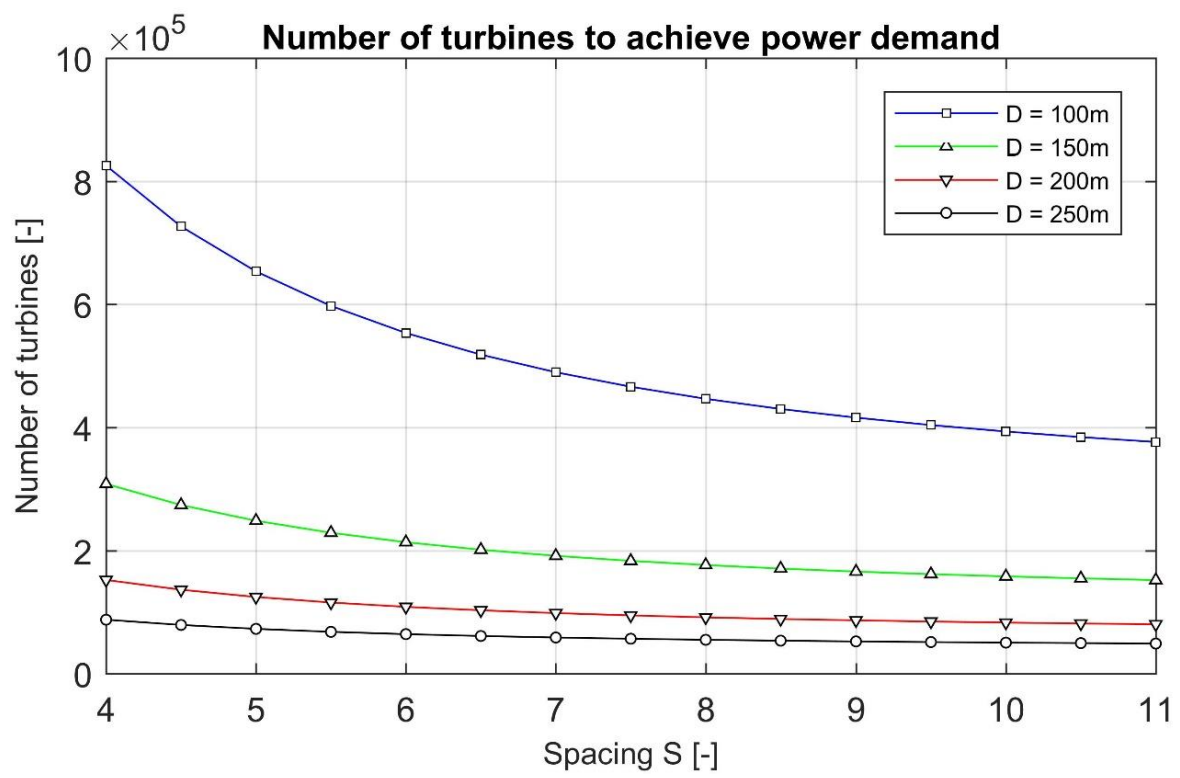

Figure 11: Number of turbines required to produce Europe's power demand as function of spacing and rotor diameter. 
Wind Energ. Sci. Discuss., https://doi.org/10.5194/wes-2018-53

Manuscript under review for journal Wind Energ. Sci.

Discussion started: 6 August 2018

(c) Author(s) 2018. CC BY 4.0 License.

475

476

Employing the various expressions of the cost model introduced in section 2.5, we here present and discuss the economic aspects of a potential massive exploitation of wind power in the North Sea. As the foundation costs increase with water depth, we will first exploit all available shallow sea bed area, and subsequently include successively deeper water regimes.

\subsubsection{Influence of water depth on cost of energy}

By combining the bathymetry of the North Sea with the cost model it is possible to determine the relative cost of energy as a function of water depth. In order to limit the number of variables we first assume a fixed rotor diameter $\mathrm{D}=200 \mathrm{~m}$, and then compute the $\mathrm{LCoE}$ for different wind turbine interspacing as a function of water depth. The result is shown in Figs. 12, from where it is seen that the LCoE increases monotonously as a function of water depth, illustrating the added expenses of the substructures at deeper waters. From Fig. 12 also seen that the LCoE reduces when placing the turbines

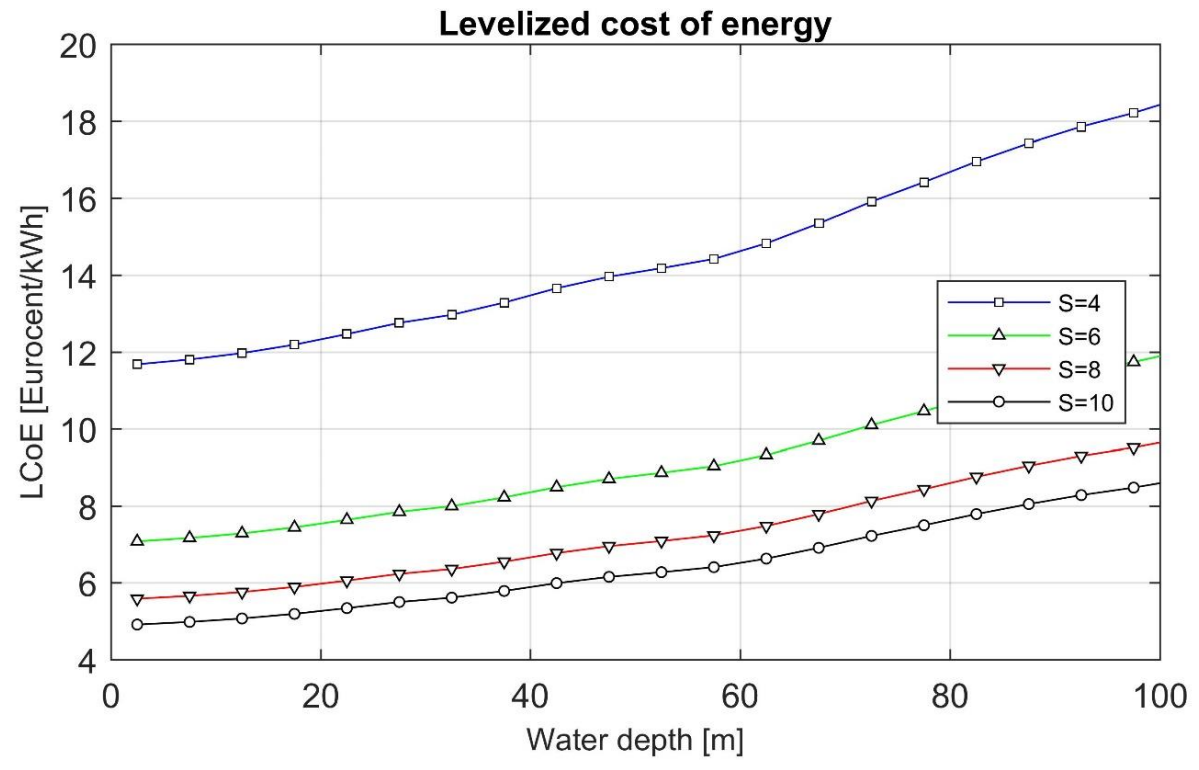

Figure 12: Levelized cost of energy (LCoE) as function of increasing water depth for a 200m diameter rotor.

further apart from each other, i.e. at increasing $S$-values. The reason for this is partly that the wind resources increase, as wake effects becomes less pronounced at higher $S$-values, and partly that the O\&M expenses decreases when erecting the turbines further away from each other, also due to less pronounced wake effects. On the other hand the cable costs increase when increasing $S$. However, this is less pronounced as compared to the decreasing cost effect of the wake effects. Fixing the interspacing at $S=8$ and varying the rotor size (Fig. 13), it is seen that the lowest cost of energy is obtained for the biggest rotor size. This can partly be explained by increased wind resources, as the tower height increases for increasing rotor diameters (it is implicitly assumed that the tower height equals the rotor diameter). From the figures, the LCoE is seen to vary from about $5 €$ cents $/ \mathrm{kWh}$ for large rotors located near the coast to nearly $13 €$ cents $/ \mathrm{kWh}$ for smaller rotors penetrating all water depths up to about $100 \mathrm{~m}$. As determined in section 3.1 it is required to exploit locations at all water depth up to about $45 \mathrm{~m}$ to comply with the electrical power demand of Europe. In this case the LCoE is found to be in the range from $6 €$ cents $/ \mathrm{kWh}$ to $9.5 €$ cents $/ \mathrm{kWh}$, depending on rotor size and the interspacing between the wind turbines. 
Wind Energ. Sci. Discuss., https://doi.org/10.5194/wes-2018-53

Manuscript under review for journal Wind Energ. Sci.

Discussion started: 6 August 2018

(c) Author(s) 2018. CC BY 4.0 License.

\section{Levelized cost of energy}

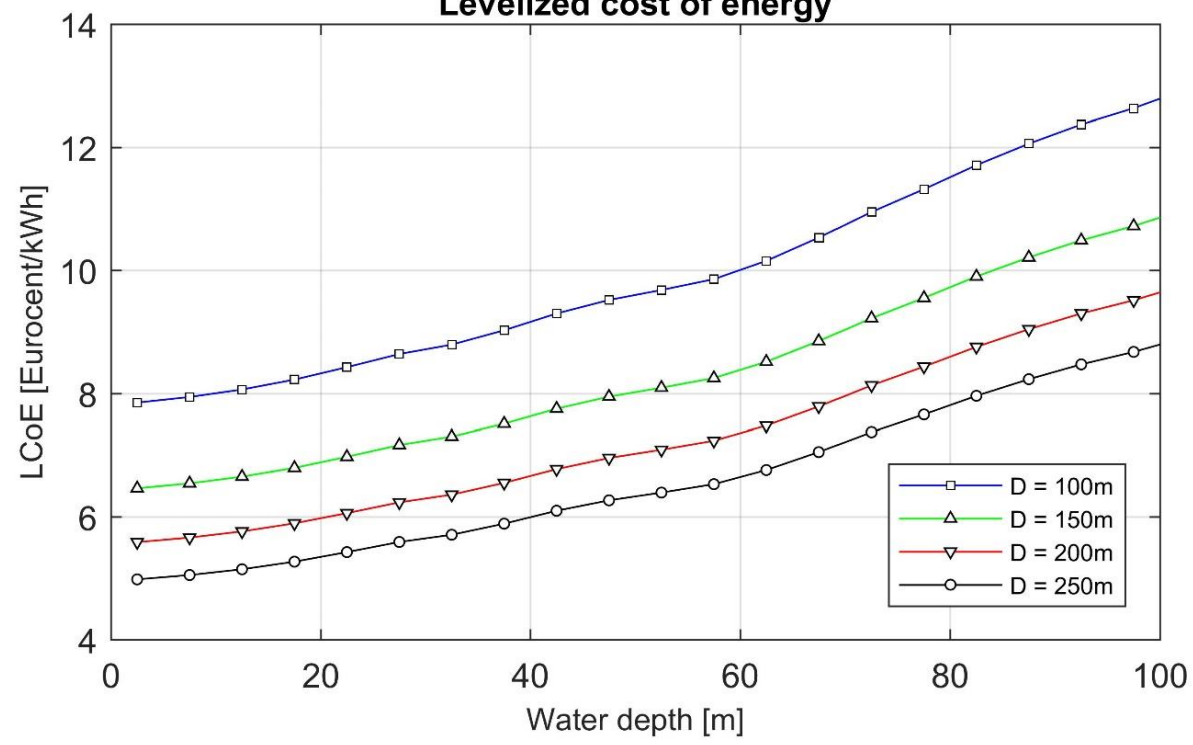

Figure 13: Levelized cost of energy $(\mathrm{LCoE})$ as function of increasing water depth for $S=8$.

It is interesting to put the computed cost estimates into perspective by looking at actual prices for existing wind farms. For an existing wind farm such as Rødsand II, which has been in operation since 2010, the cost price is about 8 $€$ cents $/ \mathrm{kWh}$. This wind farm, which covers an area of $35 \mathrm{~km}^{2}$ located on shallow waters, consists of $902.3 \mathrm{MW}$ wind turbines of diameter $93 \mathrm{~m}$ (International Renewable Energy Agency IRENA working paper, 2012). This gives an average distance between the turbines of about 7.5 diameters and a cost price of 62.9 øre/kWh (according to https://www.powertechnology.com/projects/rodsand). This cost price agrees very well with the curves shown in Fig. 13, where a wind farm consisting of $100 \mathrm{~m}$ diameter wind turbines located at water depths up to $10 \mathrm{~m}$ produces wind power to an $\mathrm{LCoE}$ which is exactly equal to $8 €$ cents/kWh. As seen in Fig.12, this price reduces with more than $30 \%$ just by increasing the rotor diameter to $200 \mathrm{~m}$.

\subsubsection{Cost of energy for covering the electricity need of Europe}

To determine the optimal combination of interspacing and rotor diameter for the required electrical power demand of Europe, we compute the $\mathrm{LCoE}$ as function of wind turbine interspacing and rotor size for a fixed electrical energy production of $\mathrm{E}=3500 \mathrm{TWh} / \mathrm{year}$. Here we have two counteracting phenomena. On one hand, LCoE decreases at increasing interspacing between the turbines. On the other hand, increasing distances between the turbines demands more space, and thus, in turn, more expensive grid installation costs are required, as well as the need to exploit the wind power at locations on larger water depths, which then tends to increase the LCoE. It is therefore expected that there will be a specific value of $S$, where the cost of energy attains a minimum. This is illustrated in Fig. 14, which depicts the LCoE as a function of wind turbine interspacing and rotor diameter to comply with Europe's total electricity demand. It is here seen that the lowest LCoE is obtained at an interspatial distance of about $S=8-9$. It is also seen, that the lowest cost of energy is obtained when increasing the rotor size. However, as mentioned above, this may partly be explained by the increased wind resources at higher hub heights, as the tower height is assumed to be equal to the rotor diameter. From the 
Wind Energ. Sci. Discuss., https://doi.org/10.5194/wes-2018-53

Manuscript under review for journal Wind Energ. Sci.

Discussion started: 6 August 2018

(c) Author(s) 2018. CC BY 4.0 License.

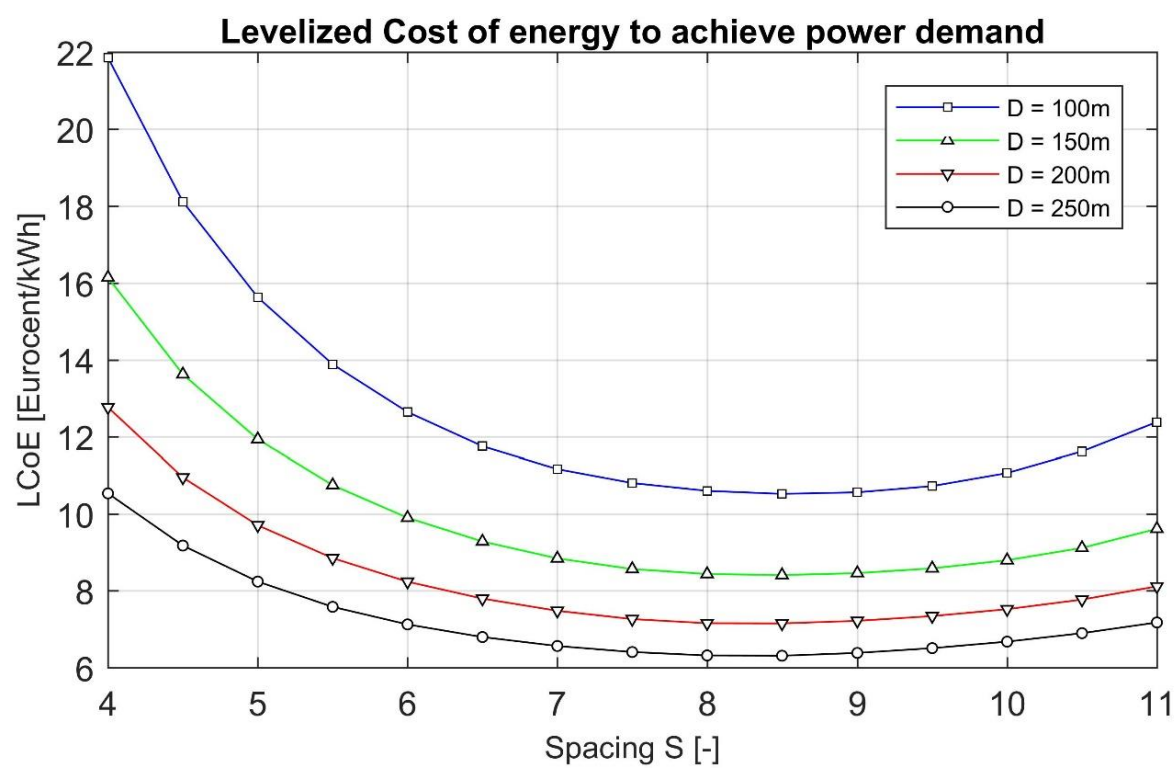

Figure 14: Levelized cost of energy (LCoE) as function of wind turbine interspacing and rotor diameter to comply with Europe's electrical energy demand of $E=3500 \mathrm{TWh} / \mathrm{year}$

figure it is seen that exploiting wind turbines of diameter $\mathrm{D}=250 \mathrm{~m}$, corresponding to an installed generator power of 20 $\mathrm{MW}$, located with an interspacing of 8 diameters, results in an estimated cost price of about $6 €$ cents $/ \mathrm{kWh}$.

\subsubsection{Assessment of relative costs}

The relative cost of the various elements involved in offshore wind energy can be assessed from the cost models introduced in section 2.5. In Fig. 15 we depict the relative costs on turbine, cables including substations, O\&M, and

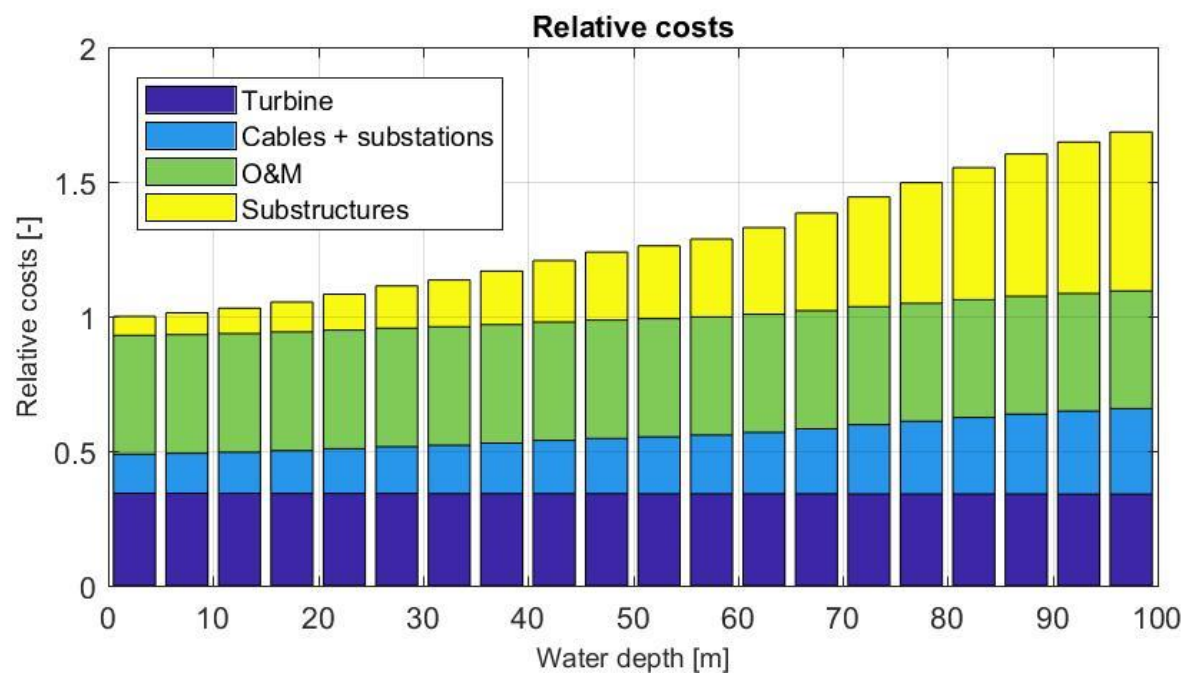

Figure 15: Relative cost of wind turbine components as function of water depth for a farm configuration consisting of wind turbines of rotor diameter $D=200 \mathrm{~m}$ and interspatial distance $S=7$. 
Wind Energ. Sci. Discuss., https://doi.org/10.5194/wes-2018-53

Manuscript under review for journal Wind Energ. Sci.

Discussion started: 6 August 2018

(c) Author(s) 2018. CC BY 4.0 License.

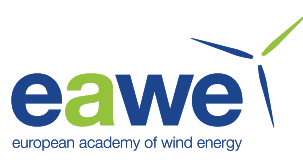

support structures as a function on water depth for a farm configuration with rotor diameter $\mathrm{D}=200 \mathrm{~m}$ and interspatial distance $S=7$. The numbers are made dimensionless by the total cost of a turbine placed on the shallowest water. Hence, the size of the bar at a given water depth refers to turbines placed on a reference water depth of $\mathrm{h}=2.5 \mathrm{~m}$. It is here seen that the total costs increases with about $20 \%$ when exploiting water depths up to $50 \mathrm{~m}$ and with about $70 \%$ for water depths up to $100 \mathrm{~m}$. It is here assumed that the support structures are limited to monopoles and jackets, following the cost model described in section 2.5.2. As the interspatial distance between the turbines is fixed, the only cost that changes at different water depths is the cost of the substructure and, to a lesser extent, the electrical substations. From the figure it is seen that the relative cost of the substructures increases from about $5 \%$ of the total costs at $\mathrm{h}=2.5 \mathrm{~m}$ to about $20 \%$ at $\mathrm{h}=50 \mathrm{~m}$.

Another way of assessing the relative costs is to fix the area and the rotor diameter and then determine the influence of the interspatial distance between the turbines on the costs of the various items. In this case it is only the operation and maintenance costs that change. This is shown in Fig. 16, which depicts the relative costs for a fixed rotor diameter $\mathrm{D}=$ $200 \mathrm{~m}$ and a total exploited area $\mathrm{A}=190.000 \mathrm{~km}^{2}$, again corresponding to water depths up to $45 \mathrm{~m}$. Note that the bars in

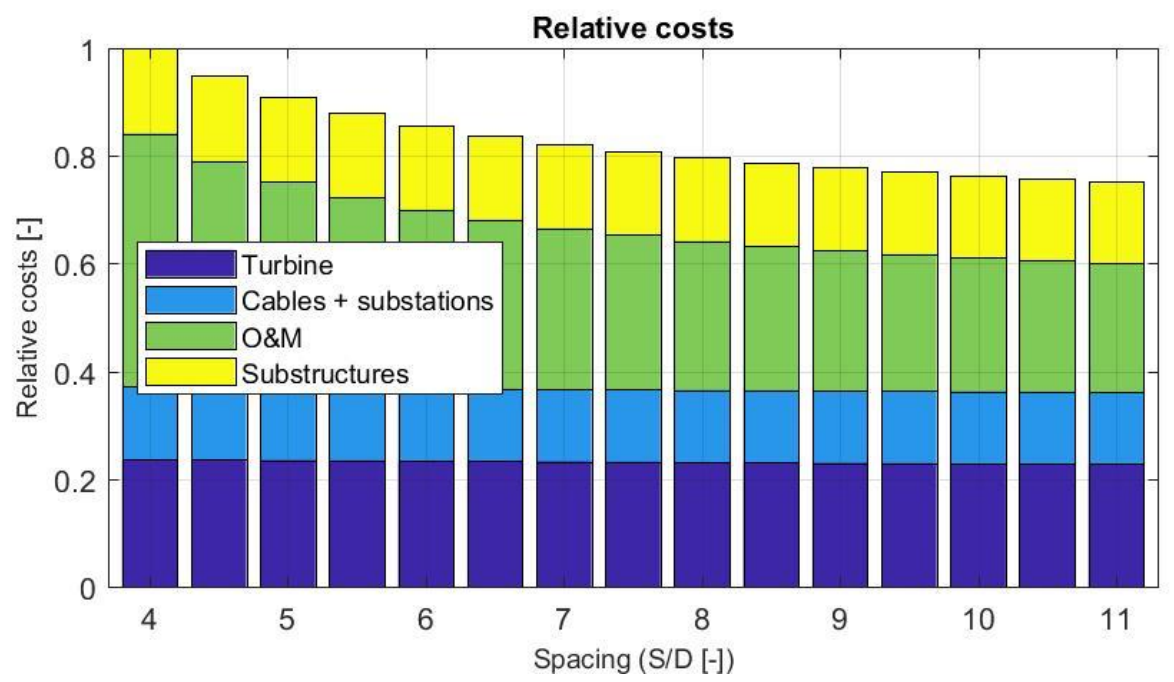

Figure 16: Relative cost of wind turbine components as function of wind turbine interspacing for a fixed rotor diameter $D=200 \mathrm{~m}$ and area $A=190.000 \mathbf{k m}^{2}$.

Fig. 16 are made dimensionless with the total costs of the configuration with the smallest investigated interspatial distance $(S=4)$. It is here seen that the total costs decreases monotonously when increasing the interspatial distance from a reference unit value at $S=4$ to about 0.75 at $S=11$. If we, as an example, take the relative cost prices at a configuration with an interspatial wind turbine distance $S=8$, which was the value with the lowest LCoE, we get that the cost of the wind turbine amounts to $23 \%$, the electrical substations including cables to $13 \%$, the substructures to $17 \%$, and the O\&M to $46 \%$ of the total costs. Hence, it is clear that the largest potential for reducing the cost price is to focus on reducing the operation and maintenance costs.

\subsubsection{Cost considerations at a fixed area}

To assess the possibility of exploiting wind power at relatively shallow waters, we here fix the exploited area up to water depths of $45 \mathrm{~m}$, corresponding to an area of the North Sea area of $190.000 \mathrm{~km}^{2}$, and compute the levelized cost of energy as a function of wind turbine interspacing for various turbine sizes. The result is displayed in Fig.17, which shows that 
Wind Energ. Sci. Discuss., https://doi.org/10.5194/wes-2018-53

Manuscript under review for journal Wind Energ. Sci.

Discussion started: 6 August 2018

(c) Author(s) 2018. CC BY 4.0 License.

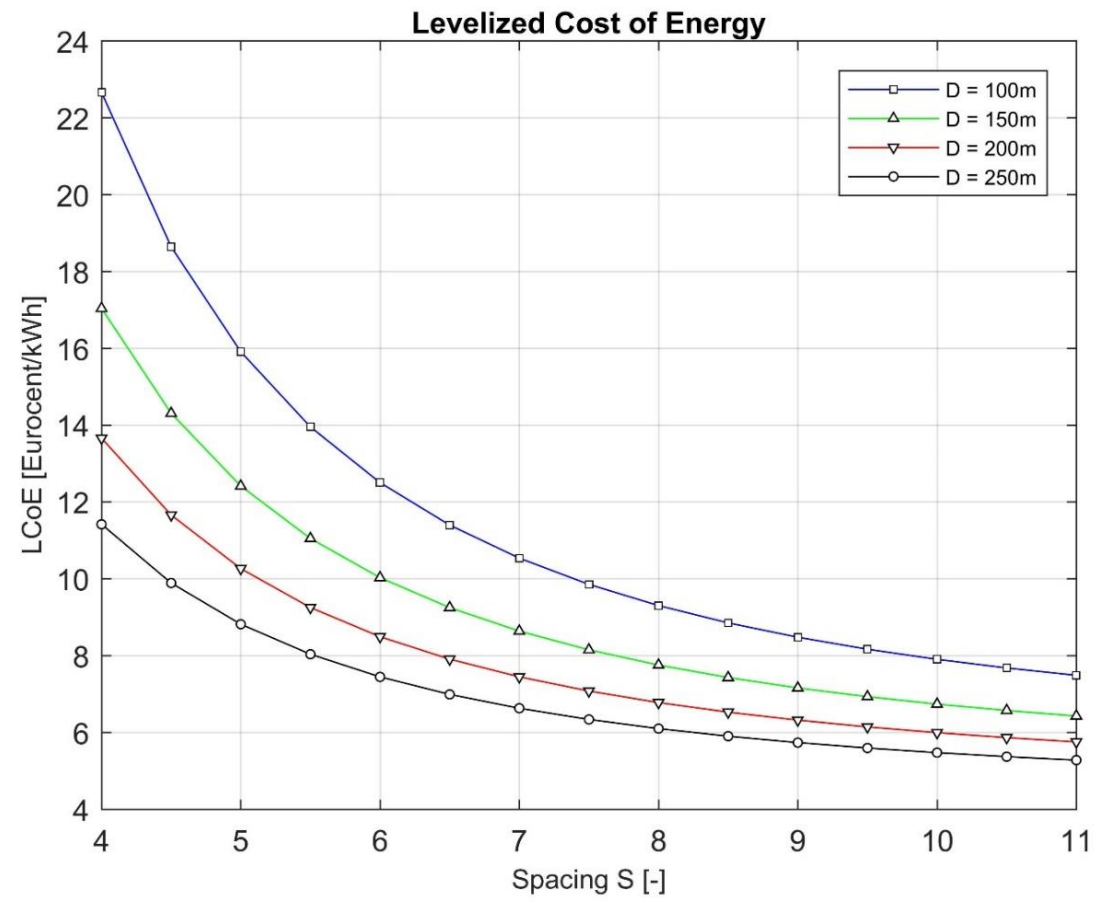

Figure 17: Levelized cost of energy as function of wind turbine interspacing for various turbine sizes at a fixed area $A=190.000 \mathrm{~km}^{2}$.

the $\mathrm{LCoE}$ decreases monotonously when increasing the wind turbine interspacing. Assuming e.g. a rotor size $\mathrm{D}=200 \mathrm{~m}$ the LCoE decreases from $14 €$ cents $/ \mathrm{kWh}$ at $S=4$ to $6 €$ cents $/ \mathrm{kWh}$ at $S=10$. Unfortunately, the total power yield also

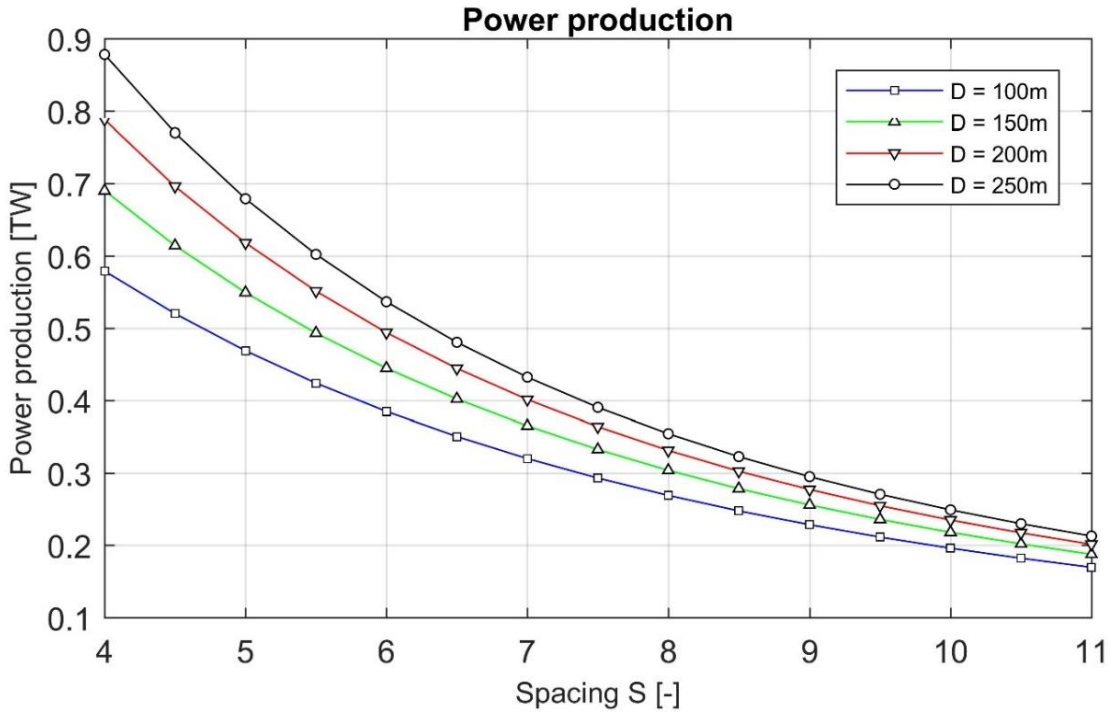

Figure 18: Power production as function of wind turbine interspacing for various turbine sizes at a fixed area $\mathrm{A}=190.000 \mathrm{~km}^{2}$. 
Wind Energ. Sci. Discuss., https://doi.org/10.5194/wes-2018-53

Manuscript under review for journal Wind Energ. Sci.

Discussion started: 6 August 2018

(c) Author(s) 2018. CC BY 4.0 License.

decreases when increasing the distance between the turbines. This is shown in Fig. 18, which depicts the power production as function of wind turbine interspacing for various turbine sizes at a fixed area $\mathrm{A}=190.000 \mathrm{~km}^{2}$. Here it is seen that the power yield for the same rotor size of $\mathrm{D}=200 \mathrm{~m}$ decreases from $0.8 \mathrm{TW}$ at $S=4$ at to $0.2 \mathrm{TW}$ at $S=11$. Combining the two figures, one may determine the LCoE to achieve a specific power demand. This is shown in Fig. 19, which displays the relative cost of energy as function of power demand for various turbine sizes, still assuming a fixed area $\mathrm{A}=$ $190.000 \mathrm{~km}^{2}$. It is seen that it is indeed possible to increase the power production to two times the present electrical power demand of Europe and still only exploit an area of $190.000 \mathrm{~km}^{2}$, corresponding to less than $1 / 3$ of the area of the North Sea. The price to pay, however, is that the levelized cost of energy increases from about $7.5 €$ cents $/ \mathrm{kWh}$ to $14 €$ cents $/ \mathrm{kWh}$ for a configuration consisting of $200 \mathrm{~m}$ diameter wind turbines with an interspacing $\mathrm{S}=4$. If North Sea instead only provides a smaller part of the electricity demand for Europe, it is seen that the LCoE decreases correspondingly. As an example, if the North Sea only is exploited to provide $50 \%$ of the European electricity demand, it is seen that the LCE may decrease to about $5.5 €$ cents/kWh for a $200 \mathrm{~m}$ rotor.

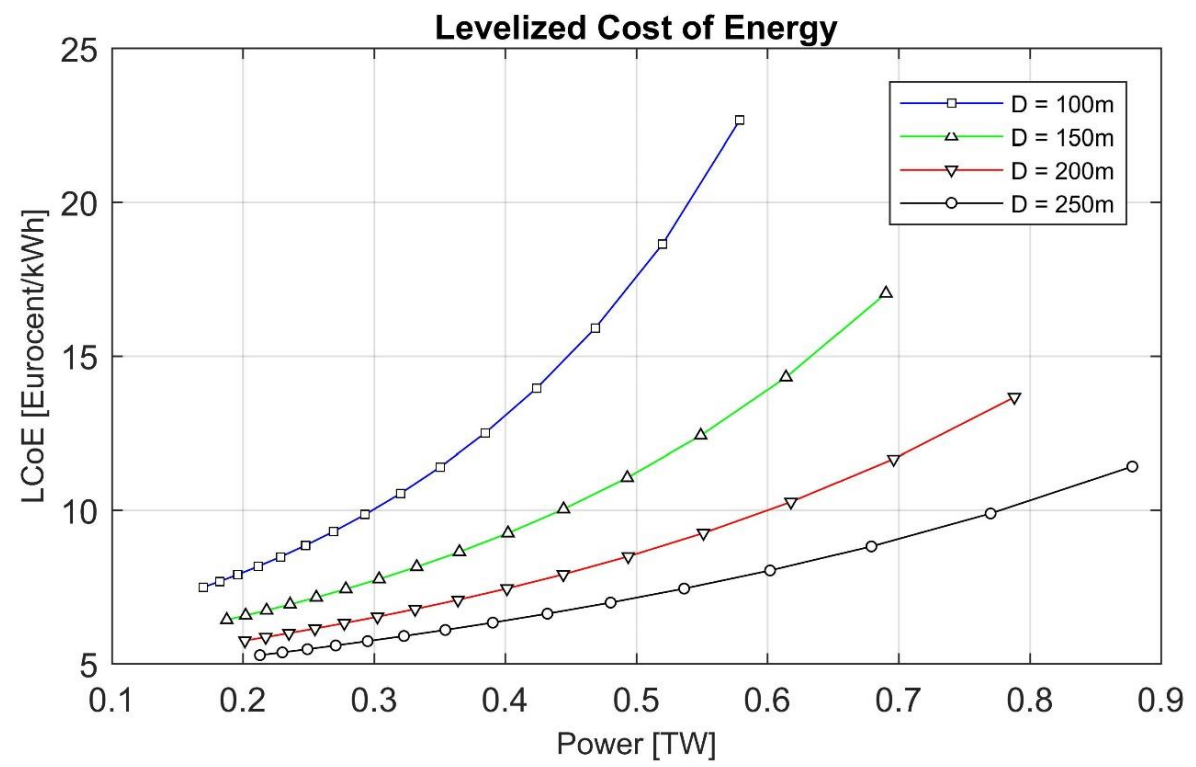

Figure 19: Levelized cost of energy as function of power demand for various turbine sizes at a fixed area $A=190.000 \mathrm{~km}^{2}$.

\section{Conclusions}

The present study focused on determining the potential of a massive exploitation of wind power in the North Sea. The study combines a simple meteorological model for large wind turbine clusters (Templin, 1974 and Frandsen and Madsen, 2003) with an economic analysis including the bathymetry of the North Sea. The analysis comprises both an assessment of the wind power potential in the North Sea and an estimate of the economics aspects associated with a large scale exploitation of wind power in the North Sea. The main parameters of the model are wind turbine size, interspatial distance between the turbines, and the area distribution on water depth. The analysis shows that the lowest cost of energy, independent of the size of the turbines, is obtained at an interspatial distance of about eight rotor diameters between the turbines. An important conclusion is that Europe's electrical power demand can be fulfilled by exploiting a surface area of $190.00 \mathrm{~km}^{2}$ with wind turbines with a rotor diameter size of $200 \mathrm{~m}$ and with an interspatial distance of 8 diameters, 
Wind Energ. Sci. Discuss., https://doi.org/10.5194/wes-2018-53

Manuscript under review for journal Wind Energ. Sci.

Discussion started: 6 August 2018

(c) Author(s) 2018. CC BY 4.0 License.

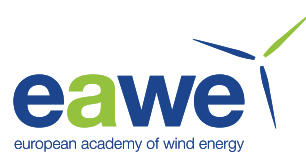

602

603

604

605

606

608

609

610

611

612

613

corresponding to $1.6 \mathrm{~km}$. This corresponds approximately to $1 / 3$ of the area of the North Sea and can be achieved by exploiting water depths less than $45 \mathrm{~m}$. The required installed power corresponds to about $100.00013 \mathrm{MW}$ wind turbines with a total installed power capacity of about $0.95 \mathrm{TW}$. Based on the presented cost model, the levelized cost of energy then amounts to about $7.5 €$ cents $/ \mathrm{kWh}$. Replacing the $13 \mathrm{MW}(\mathrm{D}=200 \mathrm{~m})$ turbines with $20 \mathrm{MW}$ turbines $(\mathrm{D}=250 \mathrm{~m})$, reduces the cost price to $6 €$ cents $/ \mathrm{kWh}$.

Another part of the study concerned the relative cost of the various items involved in offshore wind energy. Here it was found the operation and maintenance main contribute with up to $50 \%$ of the total expenses. Hence, the largest potential for reducing the cost price is to focus on reducing the operation and maintenance costs.

Finally, it was found that it is possible to increase the power production to two times the present electrical power demand of Europe and still only exploiting an area of $190.000 \mathrm{~km}^{2}$, corresponding to less than $1 / 3$ of the area of the North Sea. The price to pay, however, is that the levelized cost of energy increases from about $6 €$ cents $/ \mathrm{kWh}$ to $14 €$ cents $/ \mathrm{kWh}$ for a configuration consisting of $200 \mathrm{~m}$ diameter wind turbines with an interspacing of four diameters.

\section{Acknowledgments}

The work has been carried out with the support of the Danish Council for Strategic Research for the project Center for Computational Wind Turbine Aerodynamics and Atmospheric Turbulence (grant 2104-09-067216/DSF) (COMWIND: http://www.comwind.org). The authors like to thank Bjarke Fuglsang Nielsen for providing bathymetric data for the North Sea and Andrea Hahmann for providing the WRF-based North Sea Weibull parameters.

\section{References}

Abramowitz, M. and Stegun, I.A.: Handbook of mathematical functions. United States Dept. of Commerce, National Bureau of Standards (NBS), 1970.

Berger, R.: Offshore Wind Towards 2020; On the pathway to cost competitiveness, April 2013, http://www.rolandberger.com/media/publications/2013-05-06-rbsc-pub-ffshore_wind toward_2020.html, 2013.

Buhl, T. and Natarajan, A.: Level 0 cost models of offshore substructure - A simple cost model including water depth. DTU Wind Energy Report, 2015.

Chaviaropoulos, P. and Natarajan, A.: Definition of performance indicators (Pls) and target values. INNWIND Report (Deliverable D1.2.2), European Union's Seventh Framework Programme for research, technological development and demonstration, 2014.

Electricity in Europe 2013. ENTSOE: European Network of Transmission System Operators for Electricity. Website: https://www.entsoe.eu/Documents/Publications/Statistics/2013 ENTSO-E_Electricity\%20in\%20Europe.pdf, 2013.

European Marine Observation and Data Network (EMODnet). Website: http://portal.emodnet-bathymetry.eu/meandepth-full-coverage, 2017.

Eurostat Statistics Explained: http://ec.europa.eu/eurostat/statisticsexplained/index.php/Electricity_production,_consumption_and_market_overview, 2016.

Frandsen, S.T.: Turbulence and turbulence-generated structural loading in wind turbine clusters. Risø R-1188(EN), 2005.

Frandsen, S.T. and Madsen, P.H.: Spatially average of turbulence inside large wind turbine arrays. Proc. Europ. Seminar on Offshore Wind Energy in the Mediterranean and other European Seas (OWEMES 2003), Naples, Italy, 2003.

Frandsen, S.T., Barthelmie, R.J. and Pryor, S.C.: Energy dynamics of an infinitely large offshore wind farm. Poster presented at European Offshore Wind, Stockholm, 14 - 16 September, 2009. 
Wind Energ. Sci. Discuss., https://doi.org/10.5194/wes-2018-53

Manuscript under review for journal Wind Energ. Sci.

Discussion started: 6 August 2018

(c) Author(s) 2018. CC BY 4.0 License.

eawe'

642 Hahmann, A.: Private communication, 2017.

643 Larsen, G.C.: A simple generic wind farm cost model tailored for wind farm optimization. Technical report Risø-R-

644 1710(EN), Risø DTU, Roskilde, Denmark, 2009.

645 Larsen, G. C., Madsen, H. Aa., Thomsen, K. and Larsen, T. J.: Wake Meandering: A Pragmatic Approach. Wind

646 Energy, 11, pp. 377-395, 2008.

647 Larsen, G.C. et al.: TOPFARM - next generation design tool for optimization of wind farm topology and operation.

648 Report Risø-R-1805(EN), 2011.

649 Lundberg, S.: Performance comparison of wind park configurations. Technical report,

650 Chalmers University of Technology, 2003.

651 Mahulja, S.: Engineering an Optimal Wind Farm (Fig. 1.4). DTU Wind Energy Master Thesis, 2015.

652 Nielsen, B.F.: Private communication, 2015.

653 Pena, A. and Hahmann, A.: 30-year mesoscale model simulations of the "Noise from wind turbines and risk of

654 cardiovascular disease” project. DTU- Wind Energy Report-0055 (EN), 2017.

655 Retail prices index: http://www.dst.dk/da/Statistik/emner/prisindeks/forbrugerprisindeks-og-aarlig-inflation, 2015.

656 Rethoré, P.-E., Fuglsang, P., Larsen, G.C., Buhl, T., Larsen, T.J. and Madsen, H.Aa.:TOPFARM: Multi-fidelity

657 optimization of wind farms. Wind Energy, 17(12):1797-1816, 2014.

658 Templin, R.J.: An estimate of the interaction of windmills in widespread arrays'. N.R.C. Canada, N.A.E. Report LTR-

659 LA-171, 1974.

660 The European offshore wind industry: Key trends and statistics 1st half 2016. WindEurope. https://windeurope.org/wp-

661 content/uploads/files/about-wind/statistics/WindEurope-mid-year-offshore-statistics-2016.pdf, 2016.

662 Volker, P.: Is the Power Density of Large Offshore Wind Farms Limited? [Sound/Visual production (digital)]. The

663 Danish Wind Industry Annual Event 2014, Herning, Denmark, 26/03/2014, 2015.

664

665

666 
Wind Energ. Sci. Discuss., https://doi.org/10.5194/wes-2018-53

Manuscript under review for journal Wind Energ. Sci.

Discussion started: 6 August 2018

(c) Author(s) 2018. CC BY 4.0 License.

667

680

681

682

683

\section{Appendix A}

In this appendix the gradient of the wind farm mean wind speed, $U_{H}$ with respect to the ambient mean wind speed, $U_{H, 0}$ is proven to be positive in the above rated wind speed regime. From eq. (22) we have

$$
U_{H}=U_{H, 0} \frac{1+\frac{\gamma}{\delta}}{1+\frac{\gamma}{\kappa} \sqrt{\frac{\pi C_{T, \text { rated }}}{8 S^{2}}\left(U_{r} / U_{H}\right)^{3 / 2}+(\kappa / \delta)^{2}}},
$$

or

$$
U_{H, 0}=U_{H}\left(1+\frac{\gamma}{\delta}\right)^{-1}\left(1+\frac{\gamma}{\kappa} \sqrt{\frac{\pi C_{T, \text { rated }}}{8 S^{2}}\left(U_{r} / U_{H}\right)^{3 / 2}+(\kappa / \delta)^{2}}\right)
$$

The gradient is thus expressed as

$$
\frac{d U_{H, 0}}{d U_{H}}=\left(1+\frac{\gamma}{\delta}\right)^{-1}\left(1+\frac{\gamma}{\kappa} \sqrt{\frac{\pi C_{T, \text { rated }}}{8 S^{2}}\left(U_{r} / U_{H}\right)^{3 / 2}+(\kappa / \delta)^{2}}\right)
$$

$$
+U_{H}\left(1+\frac{\gamma}{\delta}\right)^{-1} \times\left(\frac{3}{4} \frac{\gamma}{\kappa} \frac{\pi C_{T, \text { rated }}}{8 S^{2}}\left(U_{r} / U_{H}\right)^{1 / 2}\left(\frac{U_{r}}{U_{H}^{2}}\right) \times\left(\frac{\pi C_{T, \text { rated }}}{8 S^{2}}\left(U_{r} / U_{H}\right)^{3 / 2}+(\kappa / \delta)^{2}\right)^{-1 / 2}\right)^{.}
$$

With $\gamma, \kappa, \delta, U_{r}$ and $U_{H}$ being positive, $d U_{H, 0} / d U_{H}$ is positive, and thereby $d U_{H} / d U_{H, 0}$ is positive for any (positive) value of $U_{H, 0}$ which in turn means that $U_{H}\left(U_{H, 0}\right)$ is strictly monotonic. As seen, this qualitative result has been obtained without knowing the explicit form of the function $U_{H}\left(U_{H, 0}\right)$. 